\title{
Larval responses to turbulence and temperature in a tidal inlet: Habitat selection by dispersing gastropods?
}

\author{
by Heidi L. Fuchs ${ }^{1,2}$, Andrew R. Solow ${ }^{1}$ and Lauren S. Mullineaux ${ }^{1}$
}

\begin{abstract}
Marine larval dispersal is affected by hydrodynamic transport and larval behavior, but little is known about how behavior affects large-scale patterns of dispersal and recruitment. Intertidal habitats are characterized by strong and variable turbulence relative to shelf and pelagic waters, so larval responses to turbulence may affect both dispersal and habitat selection. This study combined observations and theoretical approaches to model gastropod larval responses to multiple physical variables in a well-mixed tidal inlet. Physical measurements and larvae were collected in July 2004 in Barnstable Harbor, Massachusetts (USA). Physical measurements were incorporated in an advection-diffusion model where larval vertical velocity is a function of turbulence dissipation rate, temperature, and the temperature gradient. Modeled larval distributions were fitted to observed concentration profiles by maximum likelihood to estimate larval behavioral velocity (swimming or sinking) as a function of environmental conditions. These quantitative behavior estimates were used to test hypotheses about behavioral differences among groups and to assess the relative impact of different cues on overall larval behavior. Larvae of five common gastropod species from different coastal habitats reacted most strongly to turbulence but had genus-specific responses to environmental cues. Larvae of a species from tidal inlets (the mud snail Nassarius obsoletus) had near-zero velocities under calmer conditions and sank in strong turbulence. In contrast, larvae from exposed beach habitats (Crepidula spp. and Anachis spp.) sank in weak turbulence and swam up in strong turbulence, with additional responses to temperature and temperature gradient. Larval responses also differed between small and large size classes and between flood and ebb tides. Behavior of mud snail larvae would contribute to retention inside the inlet and near adult habitats, whereas behavior of beach snail larvae would contribute to rapid export from muddy inlets lacking suitable adult habitats.
\end{abstract}

\section{Introduction}

The behaviors of planktonic larvae affect larval vertical distributions and therefore influence dispersal patterns (Guizien et al., 2006; North et al., 2008), the supply of larvae to benthic habitats (Eckman et al., 1994; Fuchs et al., 2007; Koehl et al., 2007), and the degree to which populations are open to recruits from distant sources (Cowen et al., 2006; Gerlach et al., 2007). Despite the acknowledged role of behavior in larval transport, few details are

1. Woods Hole Oceanographic Institution, Woods Hole, Massachusetts, 02543, U.S.A.

2. Present address: Institute of Marine and Coastal Sciences, Rutgers University, New Brunswick, New Jersey, 08901, U.S.A.email: hfuchs@marine.rutgers.edu 
known about the ecological importance of larval responses to the environment. Our understanding of larval transport processes should improve through the development of coupled bio-physical models that account for behavior (Werner et al., 2007; Metaxas and Saunders, 2009). Behavior can be included in these models either by specifying some generic vertical migrations or by giving larvae an empirical response to environmental characteristics. The second approach is mechanistic and may ultimately be more useful, but it also requires that we first quantify the key behaviors affecting where larvae go. We expect that larvae respond to those cues that provide the greatest signal-to-noise ratio in their preferred habitats. For example, some intertidal habitats are characterized by strong turbulence and a large temporal variation in salinity or temperature, and larvae of intertidal species could use these signals for navigation into or away from intertidal zones (e.g., Welch and Forward, 2001).

We are particularly interested in larval responses to turbulence because turbulence clearly differentiates coastal from offshore regions and also elicits behavioral changes in some larvae. The rate of turbulent kinetic energy dissipation $\varepsilon$ is typically $\geq 10^{-1} \mathrm{~cm}^{2} \mathrm{~s}^{-3}$ in coastal areas and tidal inlets (Gross and Nowell, 1985; George et al., 1994) but rarely exceeds $10^{-2} \mathrm{~cm}^{2} \mathrm{~s}^{-3}$ in shelf regions or open ocean (Dillon and Caldwell, 1980; Oakey and Elliott, 1982). In tidal channels, turbulence varies over several orders of magnitude on short spatial (m vertical; km horizontal) and temporal (h) scales. Changes in turbulence may be sensed by larvae as differences in shear (spatial velocity gradients), acceleration, or rotation of the body. On encountering turbulence, some bivalve or snail veligers stop swimming, retract their vela, and sink (Barile et al., 1994; Young, 1995; Fuchs et al., 2004). Sinking speeds often exceed the maximum swimming speed (e.g., Hidu and Haskin, 1978; Jonsson et al., 1991), and the combination of swimming and sinking gives larvae considerable control over their vertical movements. In the laboratory, larvae of the intertidal mud snail Nassarius obsoletus shift from upward swimming to sinking at a dissipation rate of $\varepsilon \approx 10^{-1} \mathrm{~cm}^{2} \mathrm{~s}^{-3}$ (Fuchs et al., 2004). When this behavior was incorporated into a vertical advection-diffusion model for tidal channels, larvae were more concentrated near the bed and had greater settlement success in more energetic currents than in weaker flows (Fuchs et al., 2007). Turbulence is a potentially important navigational cue for dispersal and settlement in nearshore currents.

Other environmental cues are also temporally variable in tidal environments and may direct larvae towards coastal habitats. In shallow inlets, temperature and the temperature gradient vary over short time scales. For our purposes, temperature gradient refers to the rate of change rather than spatial gradient because larvae are too small to detect spatial variability. Temperature affects the swimming rates of some ciliated larvae (Young, 1995; Fingerut et al., 2003) in the laboratory. The speed of larval movement is also physiologically affected by temperature through its effects on viscosity, biochemical rates, and the ciliary beat frequency (Chia et al., 1984; Podolsky and Emlet, 1993; Larsen and Riisgård, 2009). Temperature gradient has rarely been investigated as a behavioral cue but does induce aggregation in quahog larvae (Mann and Wolf, 1983) and modify the direction of swimming in two species of crab larvae (Forward, 1990). Temperature and its gradient can be strongly 
dependent on tidal stage and may provide a tidal signal enabling larvae to tune their behaviors and move towards coastal habitats.

It remains uncertain whether responses to turbulence or temperature are an important component of larval behavior in the field, because larvae also respond to other physical cues including light (Thorson, 1964; Miller and Hadfield, 1986), pressure (Mann and Wolf, 1983; Tankersley et al., 1995), salinity (Hidu and Haskin, 1978; Tankersley et al., 1995), current shear (Pawlik and Butman, 1993), and downwelling flow (C. DiBacco unpubl. data). Larvae also change behaviors or metamorphose in response to dissolved chemical cues from conspecifics or prey species (e.g., Pawlik, 1992; Turner et al., 1994; Hadfield and Koehl, 2004). Larval responses to one cue can be modified by changes in a second or third cue (Tankersley et al., 1995; Welch and Forward, 2001), suggesting that the overall behavior is controlled by a cue hierarchy (e.g., Kingsford et al., 2002; Woodson et al., 2007). Laboratory studies using a single stimulus may be poor predictors of the overall behavior of larvae at sea, where all potential cues vary in space and time. The most important behavioral cues, i.e. those with the greatest impact on larval transport, should be definitively identified by studying larval behavior under dynamic field conditions.

Field studies of larval behavior are rare, both because natural environments are uncontrolled and because it is difficult to observe larval behaviors in situ. In the boundary layer, larval exploratory behaviors can be inferred from the location of larval settlement relative to microtopography or shear around hard surfaces (Walters, 1992; Mullineaux and Garland, 1993). Away from the substrate, however, behaviors generally are inferred from velocities measured remotely (Gallager et al., 2004; Genin et al., 2005) or from larval distributions relative to features of the water column (e.g., Cronin, 1982; Pineda, 1999; DiBacco et al., 2001). Remotely sampled data rarely allow larvae to be identified to species. Larval ecologists often theorize about behavior based on larval vertical distributions, but observed distributions provide limited insight into the relative roles of behavior and hydrodynamics or the cues that stimulate behavior. In this paper we combine highly resolved biological and physical measurements with theoretical and statistical analyses to estimate gastropod larval behaviors as a function of environmental conditions.

Our new approach was unable to account for all potential cues, so we focused on the environmental signals most likely to be used for habitat selection. The analysis was limited to three cues because some data were sparse, restricting the number of behavior parameters that could be estimated, and because the approach required enormous computation time that increased exponentially with each added parameter. Given these limitations, we focused on turbulence dissipation rate, temperature, and temperature gradient because these three cues exhibit greater spatial or temporal variability in energetic tidal inlets than in coastal currents. If coastal larvae use environmental signals to select habitats, they should respond to signals that are stronger or more variable near coastal habitats than at a distance. Although salinity also is variable in many estuaries, it was relatively constant during our study, so any responses to salinity would have been small and difficult to detect. Other physical cues such as pressure and light are arguably less variable in shallow inlets than in deeper waters, assuming that 


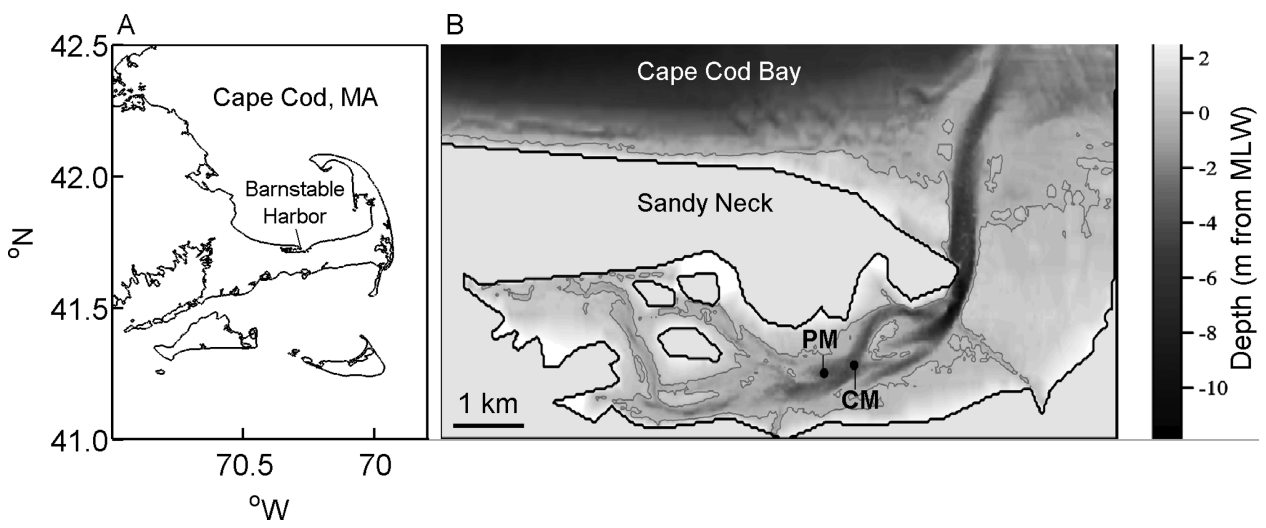

Figure 1. (A) Cape Cod map (Massachusetts, USA) showing location of Barnstable Harbor, and (B) Barnstable Harbor bathymetry map with locations of plankton mooring (PM) and current meters (CM). Black outlines indicate mean high water, gray lines indicate mean low water.

larvae move throughout the mixed layer, and chemical cues are difficult to measure in the field. We focused on turbulence and temperature because they are the physical cues most likely to provide larvae with a strong signal that they are approaching near-shore, shallow habitats.

\section{a. Field environment}

We did a field study to estimate larval behaviors in a tidally dominated, well-mixed coastal inlet at Barnstable Harbor, Massachusetts (USA; Fig. 1). The inlet has a shallow channel with a fully turbulent, depth-limited boundary layer and maximum current speeds of 50 to $80 \mathrm{~cm} \mathrm{~s}^{-1}$ (Ayers, 1959; Hunt et al., 2003). The channel runs $\sim 80^{\circ} \mathrm{WSW}$ to ENE in the inner harbor. Bed shear stresses are high and residence times are short $(\sim 5$ tidal cycles; Sanders et al., 1962), suggesting that opportunities for settlement are limited to short slack periods or brief lulls in the turbulence (e.g., Crimaldi et al., 2002). This energetic environment is inhospitable for settlement, and we suspect that benthic invertebrates can settle successfully at Barnstable Harbor only if their larvae have a behavioral mechanism to remain concentrated near the bottom while in the harbor.

The idea that larvae must remain near the bottom to recruit inside the harbor is supported circumstantially by the life histories of the most common species. Invertebrate biomass at Barnstable Harbor is dominated by direct-developing gem clams (Gemma gemma), two polychaetes with short-lived demersal larvae (Clymenella torquata and Glycera dibranchiata), and perhaps paradoxically, intertidal mud snails (Nassarius obsoletus) with planktonic larvae (Sanders et al., 1962). Juveniles and larvae of the first three species have never been observed to venture into the water column except by resuspension (e.g., Hunt, 2005) and would have limited transport in the harbor. In contrast, mud snail larvae spend 2-4 weeks 
in the plankton before they become competent to metamorphose (Scheltema, 1967). This planktonic period is longer than the residence time of water in the harbor, and larvae probably are flushed out into Cape Cod Bay and transported in coastal currents before they reach competency. When competent larvae arrive from the bay, however, sinking in strong turbulence could concentrate larvae near the bed, contributing to retention and settlement in the harbor (e.g., Fuchs et al., 2007).

As notable as mud snails' abundance in Barnstable Harbor is the absence of other adult gastropods whose larvae are plentiful in the water column. Slipper shells (Crepidula fornicata, Crepidula plana) and dove shells (Anachis avara, Anachis translirata) are common in sandy and gravelly substrates on exposed coastlines around Cape Cod; Crepidula spp. inhabit low intertidal and shallow subtidal zones, whereas Anachis spp. are mainly intertidal. We will refer to Crepidula spp. and Anachis spp. collectively as beach snails. Larvae of these groups are regularly found in plankton samples within the harbor (Fuchs unpubl. data), yet the adults are absent from Barnstable's muddy intertidal zone. Are these snails absent because the larvae settle in unsuitable muddy habitats and later suffer high mortality, or because they have low supply to the bed and low settlement due to their behavior in the water column? The absence of beach snails and abundance of mud snails may reflect differences in larval settlement success due to larval behaviors in the water column that affect retention times and delivery of larvae to the substrate.

In the present study we tested three hypotheses about behavior that have implications for how larvae are transported in Barnstable Harbor:

- $H_{1}$ : Larvae from different adult habitats respond differently to turbulence, temperature, and temperature gradient.

- $\mathrm{H}_{2}$ : Small, pre-competent larvae and large, competent larvae respond differently to environmental cues.

- $H_{3}$ : Larval responses (if any) to environmental cues depend on the tidal stage.

Our previous work on mud snails shows that turbulence-mediated sinking could enhance settlement in Barnstable Harbor. In this study, we expected that larvae from muddy inlets ( $N$. obsoletus) would sink in strong turbulence but that larvae from exposed beaches (Crepidula spp. and Anachis spp.) would have different behaviors to minimize their retention and failed settlement in the intertidal mud. We also expected precompetent and competent larvae to behave differently. If turbulence-induced sinking is a settlement behavior, then there is no a priori reason to expect a turbulence response by precompetent larvae that are physiologically unable to settle. Finally, we expected that gastropod larvae would respond differently to the environment on flood and ebb tides, because larvae could enhance their retention or export by altering their vertical movements with the changing tides.

To test our hypotheses, we estimated behaviors of early- and late-stage larvae of inletand beach-dwelling gastropods over multiple tidal cycles. Instead of observing behaviors remotely, we developed a method to estimate larval behaviors quantitatively from the vertical distributions of larvae in a turbulent boundary layer. This analysis produced population-level 
estimates of the behaviors that generated the observed larval distributions. These quantitative estimates enabled us to test hypotheses, to determine cue hierarchies, and to infer the effects of behavior on larval transport in a coastal environment.

\section{Methods}

\section{a. Larval sampling}

We sampled larvae from a small boat moored in the Barnstable Harbor channel (Fig. 1) on six days (22, 27, and 29 July and 2, 5, and 9 August) in summer 2004. Each day we sampled hourly from 07:30 to 16:30, collecting plankton samples at the surface and in 1-m increments to within a few $\mathrm{cm}$ of the bottom. Samples were collected by pumping $300 \mathrm{~L}$ of water through a $200 \mu \mathrm{m}$-mesh plankton net (Ebara Dominator pump, Great Plains Industries TM200 flowmeter). A downrigger (Scotty Strongarm) was used to set the pump at precise depths. Plankton samples were stored overnight at $4{ }^{\circ} \mathrm{C}$, fixed in $4 \%$ formalin with borax buffer for up to 2 weeks, and then transferred to buffered $80 \%$ ethanol.

Later we sieved the samples into small and large size fractions $(200-425 \mu \mathrm{m}$ and $>425 \mu \mathrm{m}$ ), sorted them, and identified gastropod larvae to species using previous descriptions (Scheltema, 1962, 1969; Thiriot-Quievreux and Scheltema, 1982). The two size fractions correspond to the approximate sizes of pre-competent and competent mud snail larvae. Samples from 22 July were poorly preserved and could be identified only to class, and August samples had few larvae, so we present only the data from 27 and 29 July. These sampling periods include two complete ebb tides and three partial flood tides mid-way between neap (24 July) and spring (1 August) tides. We found larvae of mud snails (Nassarius obsoletus), slipper shells (Crepidula plana and C. fornicata), and dove shells (Anachis avara and A. translirata) in at least half the profiles and used them for behavioral analyses. Crepidula spp. and Anachis spp. had low abundances and were pooled by genus.

\section{b. Physical measurements}

In order to quantify larval responses to turbulence, we needed physical measurements that would resolve both the vertical mixing and the small-scale turbulence that larvae might respond to. We measured near-bottom velocities with an acoustic Doppler velocimeter (5$\mathrm{MHz}$, Sontek ADVOcean) and measured velocity profiles with an acoustic Doppler current profiler (1.2-MHz, RDInstruments Workhorse ADCP). The instruments were deployed in the Barnstable Harbor channel in July 2004 and collected data from 22 July to 31 July. The ADV measured velocities at $\sim 0.78 \mathrm{~m}$ above the bed (mab) in earth coordinates at $8 \mathrm{~Hz}$ for 512 -s bursts every half hour. About $10 \mathrm{~m}$ due north $\left(0^{\circ}\right)$ of the ADV, the ADCP was bottommounted on a tripod and leveled to a $\sim 2^{\circ}$ tilt, within the acceptable limits for Reynolds stress calculations (Lu and Lueck, 1999b). The ADCP operated in mode 12 and averaged $10-\mathrm{Hz}$ sub-pings every second, recording beam velocities every other second. To resolve the shallow water column we used a $25-\mathrm{cm}$ bin size, with the first bin at $1.5 \mathrm{mab}$. The ADV provided more accurate turbulence estimates, but by using the ADCP to estimate Reynolds 
stresses we were also able to resolve the vertical structure of turbulence dissipation rates and eddy diffusivities.

i. ADV data analysis. The ADV measured pressure and 3-dimensional velocities near the bed. The pressure records were spiky and could not be used to estimate wave height, but little or no wave signal was apparent in the ADV velocity spectra (described in the next paragraph). Weather was mild during the study period, with daily-average wind speeds of 1.7 to $6.1 \mathrm{~m} \mathrm{~s}^{-1}$ and variable daily-average wind direction $\left(20^{\circ} \mathrm{NNE}\right.$ to $210^{\circ} \mathrm{SSW}$; Barnstable Weather Station, http://www1.ncdc.noaa.gov). On larval sampling days 27 and $29 \mathrm{July}$, winds were light and shifted from the $\mathrm{E}\left(90^{\circ}\right)$ in the morning to NW $\left(320^{\circ} ; 27 \mathrm{July}\right)$ to WNW $\left(295^{\circ} ; 29\right.$ July) in the afternoon. We de-spiked the pressure records and averaged over each burst to estimate the water depth $H$ (converted from pressure).

The ADV velocity sensor worked properly, but the sensor head occasionally was obstructed by crabs or floating algae (P. Schultz pers. comm.). We pre-processed the data to eliminate low-quality velocity measurements as in Elgar et al. (2001). Whole bursts were excluded if they contained more than $33 \%$ bad data or if any of the velocity standard deviations changed by a factor of $\geq 2$ after processing. By these criteria, 29\% of bursts showed evidence of sensor obstruction and were discarded. Velocities were rotated to cartesian coordinates where $u(t)$ is the along-current velocity (positive towards Cape Cod Bay, $82^{\circ}$ $\mathrm{E}), v(t)$ is the cross-current velocity, and $w(t)$ is the vertical velocity.

We calculated mean velocities, shear velocity, and the dissipation rate for each 512-s burst. For discarded bursts we still calculated mean velocities with the assumption that sensor noise is Gaussian with zero mean. After de-meaning and de-trending the velocity series, we estimated the shear velocity $u_{*}$ as $u_{*}=\sqrt{\left|\overline{u^{\prime} w^{\prime}}\right|}$ (the covariance method), where $u^{\prime}$ and $w^{\prime}$ are the along-current and vertical velocity fluctuations and the overbar indicates a temporal average. We estimated the dissipation rate $\varepsilon_{w}$ from the one-sided wavenumber spectrum $E_{w}$ of vertical velocity by fitting:

$$
E_{w}=\alpha\left(\frac{24}{55}\right) \varepsilon_{w}^{2 / 3}\left(k^{-5 / 3}+\left(k_{s}-k\right)^{-5 / 3}\right)
$$

in the inertial subrange (Trowbridge et al., 1999). Here $\alpha \approx 1.5$ is an empirical constant (Grant et al., 1962), $k$ is the wavenumber (related to frequency $f$ by $k=2 \pi f /|U|$ where $U$ is the mean current velocity; Taylor's frozen turbulence hypothesis), and $k_{s}$ is the wavenumber corresponding to the sampling frequency. The $w$ spectra were unaffected by noise but showed some aliasing at higher flow velocities; the wavenumber term of (Eq. 1) was corrected for aliasing. We also estimated $\varepsilon_{u}$ and $\varepsilon_{v}$ from the noise-corrected $u$ and $v$ spectra (Trowbridge et al., 1999) and rejected a small number $(\sim 4 \%)$ of bursts where the three spectral dissipation estimates disagreed. Disagreements among the three dissipation estimates occurred only at or near slack tides, when the dissipation rate was sensitive to small differences in the velocity time series. The remaining estimates produced excellent agreement between $\varepsilon_{u}, \varepsilon_{v}$, and $\varepsilon_{w}$; we used $\varepsilon_{w}$ in our analyses. 
ii. ADCP data analysis. The ADCP measured velocity and turbulence profiles in the water column. For the calculation of mean current velocities and shear, we transformed velocities from beam to cartesian coordinates with corrections for pitch and roll ( $\mathrm{Lu}$ and Lueck, 1999a; Stacey et al., 1999). Current velocities were rotated to coordinates where $u(z, t)$ is the along-current velocity, $v(z, t)$ is the cross-current velocity, and $w(z, t)$ is the vertical velocity (positive upwards), and 10-minute average velocities $U(z, t), V(z, t)$, and $W(z, t)$ were calculated for each depth bin. We calculated the Reynolds stress $\overline{u^{\prime} w^{\prime}}$ from the ADCP beam velocities over 10-minute intervals using the variance method (e.g., Lu and Lueck, 1999b; Stacey et al., 1999). The 10-minute interval is a compromise between the need to resolve turbulent events and the requirement that turbulence be stationary (statistically time-invariant) during the interval (Stacey et al., 1999; Rippeth et al., 2002). We estimated shear velocity directly from the Reynolds stress in the bottom bin as $u_{*}=\sqrt{\left|\overline{\mid u^{\prime} w^{\prime}}\right|}$. Both the eddy diffusivity and dissipation rate were estimated as functions of the Reynolds stress and the along-current velocity shear $\partial U / \partial z$. The vertical eddy diffusivity $K_{p}$ is defined as:

$$
K_{p}=-\overline{u^{\prime} w^{\prime}} / \frac{\partial U}{\partial z} .
$$

We expected the dissipation rate $\varepsilon_{p}$ to be in balance with the production of turbulent kinetic energy (e.g., Trowbridge et al., 1999), estimated as:

$$
\varepsilon_{p}=-\overline{u^{\prime} w^{\prime}} \frac{\partial U}{\partial z}
$$

Lastly, we smoothed $K_{p}$ and $\varepsilon_{p}$ using a triangular filter. We used a filter window of [ $z-2 \Delta z$ to $z+2 \Delta z, t-2 \Delta t$ to $t+2 \Delta t]$ and weights of $w_{z \pm \Delta z, t \pm \Delta t}=2 / 3 w_{z, t}$ and $w_{z \pm 2 \Delta z, t \pm 2 \Delta t}=$ $1 / 3 w_{z, t}$, where $\Delta z=25 \mathrm{~cm}$ is the ADCP bin size and $\Delta t=10 \mathrm{~min}$ is the burst interval.

iii. Temperature. We measured hourly conductivity, temperature, and depth (CTD; Ocean Sensors OS200) profiles at the plankton station during each larval profile. These profiles confirmed that the water column was well-mixed most of the time (Fuchs, 2005, Fig. 4-3). Of the 20 profiles collected on 27 and 29 , one profile showed some stratification $\left(\sim 1^{\circ}\right.$ difference between surface and bottom) at high tide. The ADCP provided a continuous record of nearbottom temperature at the current meter site. The near-bottom temperature from the ADCP was comparable to the depth-averaged temperature from the CTD (Appendix), so we used the ADCP temperature record in our analyses.

\section{c. Behavior analysis}

The goal of this analysis is to model larval behavior as a response to turbulence and temperature and to use this model to test for specific behavioral differences between taxa and size classes and with tidal state. The analysis incorporates highly resolved observations of turbulence, temperature, and larval concentration distributions in Barnstable Harbor. 
Table 1. Number of profiles containing larvae and number of larvae captured for each taxon and size class. Some profiles had too few larvae to analyze; numbers of profiles and larvae analyzed indicated in parentheses.

Taxon

Nassarius obsoletus

Crepidula spp.

Anachis spp.
Size

small

large

small

large

small

large
\# Profiles

$16(13)$

$14(7)$

$16(8)$

$10(2)$

$16(10)$

$12(5)$
\# Larvae

1007 (996)

89 (77)

$326(305)$

48 (17)

$352(339)$

79 (63)

Statistical inference here is based on the 1-dimensional advection-diffusion (AD) equation:

$$
\frac{\partial C}{\partial t}=-\frac{\partial}{\partial z}\left(w C-K \frac{\partial C}{\partial z}\right)
$$

where $C(z, t)$ is the concentration of larvae at height $z$ and time $t, w(z, t)$ is vertical advection velocity due to larval behavior, and $K(z, t)$ is eddy diffusivity. We must specify how $w$ depends on environmental conditions. Turbulence affects behavior of mud snail larvae in the laboratory, and in the field larval behavior may be modulated by tide-dependent cues such as temperature. To capture the potential dependence of $w$ on small-scale turbulence and temperature, we assume that:

$$
w=\theta_{0}+\theta_{1} \log _{10} \varepsilon+\theta_{2}\left(\log _{10} \varepsilon\right)^{2}+\theta_{3} T^{\prime}+\theta_{4} d T / d t+\epsilon
$$

where $\theta_{i}$ are parameters to be estimated, $\varepsilon$ is dissipation rate, $T^{\prime}$ is the depth-averaged temperature anomaly relative to the average recorded temperature $\left(20^{\circ} \mathrm{C}\right), d T / d t$ is the temperature gradient, and $\epsilon$ is an error term.

Ideally the behavior model (Eq. 5) would include all possible cues, but there are practical limits on the model's complexity. First, it would be unreasonable to estimate too many parameters using sparse data, and large larvae were found in only a subset of the profiles (Table 1). Second, each additional parameter requires an exponential increase in computation time. Given these limitations, we included the three cues that were quantifiable and had the greatest variability during the field study. We add a squared dissipation rate term to account for the possibility of a nonlinear response to turbulence, as suggested by laboratory data (Fuchs et al., 2004). We used linear responses to temperature and its gradient because there is little evidence to the contrary. The behavior model is unbounded, but in reality there is a physical limit to larval swimming and sinking speeds. A bounded function requires at least four parameters, and it would be infeasible to use a bounded form with multiple behavior cues. Instead of limiting our model to a single cue with a complex response, we used a simple function that accounts for multiple cues. 
We make three additional assumptions. First, we assume that particles with zero velocity would be evenly distributed in the water column and that departures from an even distribution are due to swimming or sinking. This amounts to the assumption that the water column is well mixed. This assumption is consistent with CTD profiles taken in Barnstable Harbor in conjunction with larval samples. Of the 20 profiles collected on 27 and 29 July, all were vertically uniform except one (Fuchs, 2005). The profile associated with the exception occurred shortly after high tide and showed slight stratification $\left(1^{\circ} \mathrm{C}\right.$ temperature difference between surface and bottom). We omitted the corresponding plankton profile from the subsequent analysis to satisfy the well-mixed assumption. Second, we assume that larval diffusivity is equal to fluid diffusivity. This implies that the transport of larvae by eddies is free of particle inertia and crossing-trajectory effects. Conservative calculations based on the theory in Ross and Sharples (2004) and Csanady (1963) indicate that both inertial and crossing-trajectory effects are negligible in our data. Finally, in common with other plankton studies (e.g., Genin et al., 2005), we assume that currents in Barnstable Harbor are laterally homogeneous over the spatial scale of our data. This assumption was confirmed by an $\sim 8$-h survey of the entire Barnstable Harbor channel using a boat-mounted, down-looking ADCP. Despite variations in depth through the channel, the current velocities were consistent over 10-min time periods corresponding to about $1.2 \mathrm{~km}$ of distance traveled (Fuchs, unpubl. data).

We simulated the expected larval distributions by running the $\mathrm{AD}$ model (Eq. 4) with the behavior function (Eq. 5) and the appropriate physical forcing $(K, \varepsilon, T$, and $d T / d t)$ for time periods corresponding to the larval observations. Because the field measurements of the turbulence and temperature terms were discrete in time and space, we fitted high-order response surfaces to them (Appendix) and forced the AD model by the fitted values. We used no-flux boundary conditions because we assumed the mixing time scale $\left(\approx H^{2} / \mathrm{K}\right.$, where $H$ is water depth; Tennekes and Lumley, 1972) was shorter than the settlement time scale. This assumption probably is correct except briefly during slack tides. We solved Eq. 4 numerically using the Matlab 7 partial differential equation solver; for additional details, see Fuchs et al. (2007). The Matlab equation solver cannot accommodate variable watercolumn depth, so we used a constant depth of $4 \mathrm{~m}$, approximating the mean depth where the larval data were collected. The simulated concentration distributions were sampled at the same proportional depths $(z / H)$ where larvae were collected, and sample concentrations were normalized by the total in each profile to obtain probability distributions used in the behavior analysis (see next paragraph). A constant-depth model accurately predicts the depth-normalized larval profiles in a water column of variable depth, as we verified using a particle-tracking equivalent of the AD model (e.g., Fuchs, 2005). We repeated the simulations for combinations of behavior parameters that bracketed a reasonable range of larval velocities, given the measured dissipation rates and temperatures.

The next step is to determine what modeled larval behaviors produce simulated larval distributions that best match the field observations. Suppose that, in profile $j$ taken at time $t_{j}$, larval samples are collected at each of $m$ depths $z_{j 1}, z_{j 2}, \ldots, z_{j m_{j}}$. To be comparable to 
the model results, these depths have been divided by the corresponding water column depth and multiplied by the model depth $(4 \mathrm{~m})$. Let $n_{j k}$ be the number of larvae collected at depth $z_{j k}$. Conditional on the total number $n_{j}=\sum_{k=1}^{m_{j}} n_{j k}$ of larvae, we assume that the vector of counts $\left(n_{j 1} n_{j 2} \ldots n_{j m_{j}}\right)$ is a realization of a multinomial random variable with $n_{j}$ trials and probabilities $\left(p_{j 1} p_{j 2} \ldots p_{j m_{j}}\right)$ where:

$$
p_{j k}=C\left(z_{j k}, t\right) / \sum_{k=1}^{m_{j}} C\left(z_{j k}, t\right) .
$$

In other words, if we collect a total of $n_{j}$ larvae in a profile of $m_{j}$ discrete samples, then each larva has a multinomial probability $p_{j k}$ of being captured in sample $k$, where $p_{j k}$ are defined by the underlying concentration distribution. Although it is suppressed in the notation, these probabilities depend on the parameters of the behavioral model (Eq. 5). As described next, the goal is to use the data in likelihood-based inference about these parameters. Likelihoodbased inference under the multinomial model is described by McCullagh and Nelder (1989).

Let $\Theta$ be the vector of parameters of the behavioral model. The log likelihood function for the model outlined above is:

$$
\log L(\Theta)=\sum_{j=1}^{J} \sum_{k=1}^{m_{j}} n_{j k} \log p_{j k}(\Theta)
$$

where we have now extended the notation to make explicit the dependence of the multinomial probabilities on $\Theta$. The maximum likelihood (ML) estimate of $\hat{\Theta}$ is found by numerically maximizing $\log L(\Theta)$ over $\Theta$.

The $\hat{\Theta}$ can be used to predict the larval velocity $w$ as a function of environmental conditions with some uncertainty, and we quantified this uncertainty in two ways. First, we estimated a $90 \%$ confidence interval for each parameter $\theta_{i}$ using the profile likelihood (e.g., McCullagh and Nelder, 1989). Second, we estimated a $90 \%$ prediction interval for the larval velocity using a parametric bootstrap. Larval distributions were simulated with larval velocity $\hat{w}=f(\hat{\Theta}, \varepsilon, T, d T / d t)$, and these simulations give the probability distribution of larvae in each profile. Using the probability distributions and the number of larvae captured in each profile, we did multinomial sampling to generate 100 bootstrap data sets. Finally we fitted the behavior model (Eq. 5) to the bootstrap data as described above to get new parameter estimates $\hat{\Theta}^{\prime}$, that can be used to estimate the sampling distributions of the error term $\epsilon$ and of the prediction interval for $w$.

i. Hypotheses. A likelihood ratio (LR) was used to test for behavioral differences between larval groups. The LR statistic for testing a null hypothesis $H_{0}$ about $\Theta$ against an alternative hypothesis $H_{1}$ is:

$$
\Lambda=2\left(\log L\left(\hat{\Theta}_{1}\right)-\log L\left(\hat{\Theta}_{0}\right)\right)
$$


where $\hat{\Theta}_{0}$ and $\hat{\Theta}_{1}$ are the ML estimates of $\Theta$ under $H_{o}$ and $H_{1}$, respectively. The LR statistic $\Lambda$ has an approximate $\chi^{2}$ distribution with degrees of freedom given by the difference in the number of parameters estimated under $H_{1}$ and the number estimated under $H_{0}$.

We tested three hypotheses about behaviors of Nassarius obsoletus, Crepidula spp. (C. fornicata and C. plana pooled), and Anachis spp. (A. avara and A. translirata pooled). First, we suspect that these gastropod larvae have behavioral adaptations for successful transport into their preferred adult habitats (muddy inlet vs. exposed beach), so we hypothesized that their larvae exhibit different behaviors $\left(H_{1}\right)$. We tested this hypothesis for pairwise combinations of $N$. obsoletus, Crepidula spp., and Anachis spp. in small (200-425 $\mu \mathrm{m})$ and large $(>425 \mu \mathrm{m})$ size fractions for flood-tide samples, ebb-tide samples, and all samples combined. Second, we suspect that turbulence-induced sinking is a settlement behavior, so we hypothesized that small, pre-competent larvae and large, competent larvae would exhibit different behaviors $\left(H_{2}\right)$. We tested this hypothesis for the flood-tide samples, ebbtide samples, and all samples combined for each larval group. Third, we are interested in whether larval behavior aids transport in tidal environments, so we hypothesized that the larval responses to physical cues are different on flood and ebb tides $\left(H_{3}\right)$. We tested this hypothesis for small and large size fractions of each taxon. The null hypothesis $\left(H_{0}\right)$ is always that there are no behavioral differences between groups.

ii. Contributions of different responses to overall behavior. In order to understand the cue hierarchy that determines larval behavior, we needed some quantitative measure of the relative importance of different cues. We characterized this hierarchy simply by estimating how much each response contributed to the overall larval velocity in the behavior model (Eq. 5). The velocity $w$ includes fractional contributions from the constant term and from responses to turbulence, temperature, and temperature gradient, given by:

$$
\begin{aligned}
\alpha_{c} & =\frac{\hat{\theta}_{0}}{w} \\
\alpha_{\varepsilon} & =\frac{\hat{\theta}_{1} \log _{10} \varepsilon+\hat{\theta}_{2}\left(\log _{10} \varepsilon\right)^{2}}{w} \\
\alpha_{T} & =\frac{\hat{\theta}_{3} T^{\prime}}{w} \\
\alpha_{d T / d t} & =\frac{\hat{\theta}_{4} d T / d t}{w} .
\end{aligned}
$$

These fractional velocities are time- and space-dependent; we averaged them over all sampling periods and depths to get mean values of $\left\langle\overline{\alpha_{c}}\right\rangle,\left\langle\overline{\alpha_{\varepsilon}}\right\rangle,\left\langle\overline{\alpha_{T}}\right\rangle$, and $\left\langle\overline{\alpha_{d T / d t}}\right\rangle$. While the average estimates can be positive or negative, their relative magnitudes reflect the strength of larval responses to different environmental cues. We took absolute values of the average estimates and divided them by their sum to get response weights $B=\left[\beta_{c}, \beta_{\varepsilon}, \beta_{T}, \beta_{d T / d t}\right]$. Each weight represents a time- and space-averaged fraction of the overall behavior that is contributed by a larval response to an individual cue. We quantified uncertainty in the response weights by re-calculating $B$ using the bootstrap estimates $\hat{\Theta}^{\prime}$. 

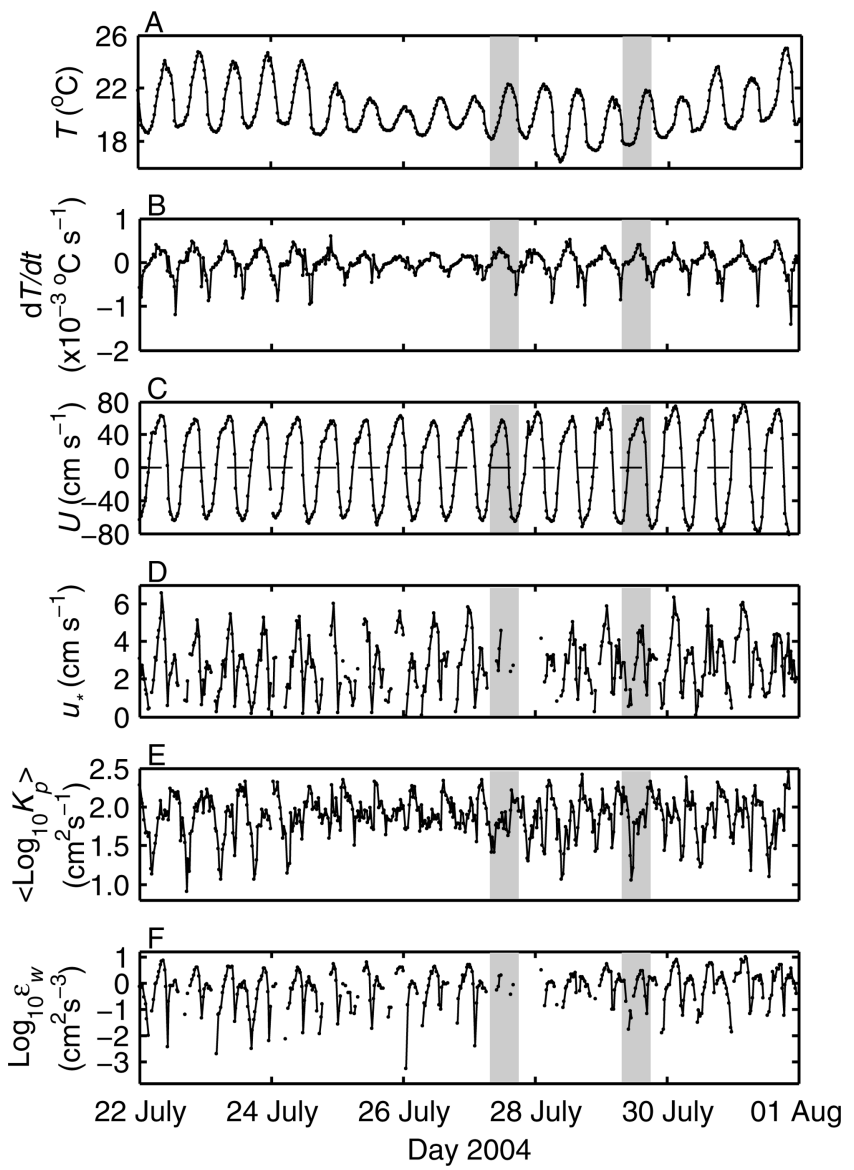

Figure 2. July measurements of (A) temperature $T$ (ADCP), (B) temperature gradient $d T / d t$ (ADCP), (C) surface current velocity $U$ (ADCP, positive on ebb tides), (D) shear velocity $u_{*}=\sqrt{\left|u^{\prime} w^{\prime}\right|}$ (ADV), (E) depth-averaged eddy diffusivity $\left\langle\log _{10} K_{p}\right\rangle$ (ADCP), and (F) dissipation rate $\varepsilon_{w}$ (ADV, $z=0.78 \mathrm{~m})$. Missing data points were discarded because of excessive noise. Shaded gray boxes indicate plankton sampling periods.

\section{Results}

\section{a. Physical measurements}

The water column at Barnstable Harbor was well mixed, and tides were asymmetric and flood-dominated. Salinity and temperature profiles were nearly vertical except for a profile collected near high tide on 29 July that was slightly stratified. Salinity was 29.9 to 31.0 and varied by no more than about 1 over any 10-h sampling period, indicating low freshwater inflow into the harbor. Temperature varied by up to $6^{\circ} \mathrm{C}$ between high and low tides (Fig. 2A) due to rapid warming of the shallow inlet during low tides. The temperature gradient was 


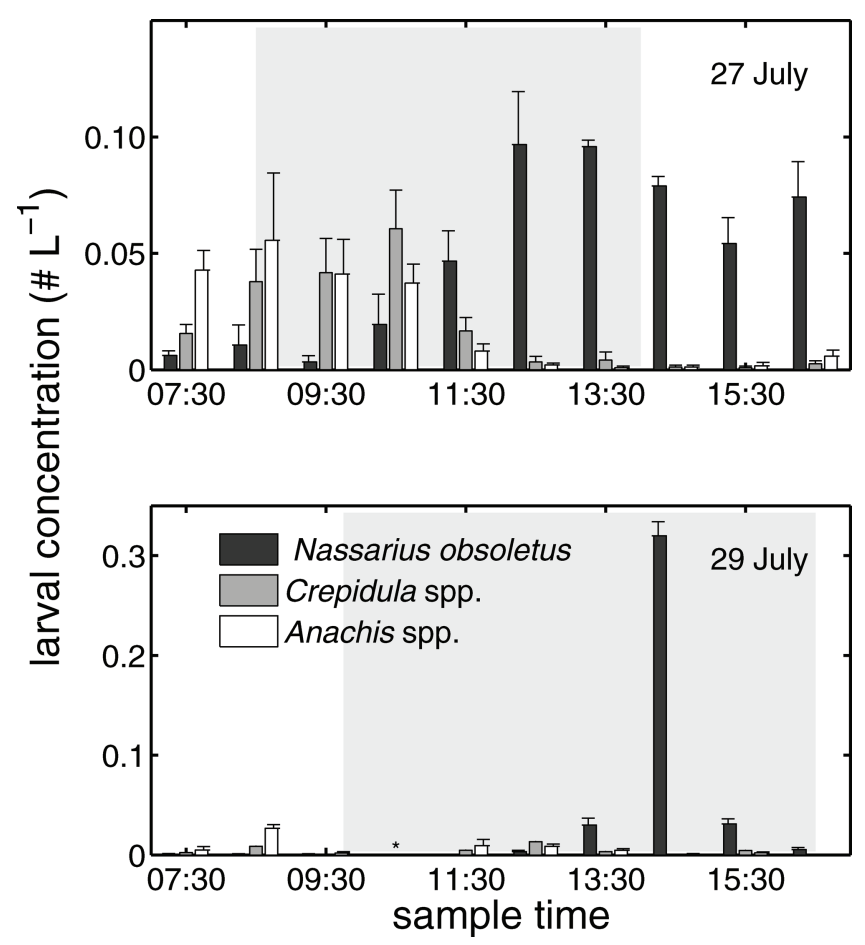

Figure 3. Time series of average larval concentration $\left(\# \mathrm{~L}^{-1}\right)$ in each profile on 27 and 29 July. Size classes are pooled.

positive on ebb tides and negative on flood tides (Fig. 2B) and would be a reliable indicator of tidal stage for larvae within the harbor. Current velocities reached a maximum of about $80 \mathrm{~cm} \mathrm{~s}^{-1}$ on spring tide (Fig. 2C) with shear velocities up to about $6.6 \mathrm{~cm} \mathrm{~s}^{-1}$ (Fig. 2D). The eddy diffusivity $K_{p}$ had maxima at mid-depth on flood tides and near the surface and bottom on ebb tides, with depth-averaged values of $\sim 10^{2}$ to $\sim 10^{2.5} \mathrm{~cm}^{2} \mathrm{~s}^{-1}$ on peak tides (Fig. 2E). Diffusivities were generally much lower on high tides than on low tides. Near the bed, dissipation rates $\varepsilon_{w}$ from ADV velocity spectra ranged from $10^{-3.2}$ to $10^{1.0} \mathrm{~cm}^{2} \mathrm{~s}^{-3}$ with higher values on ebb tides than on flood tides (Fig. 2F).

\section{b. Plankton profiles}

Larvae were temporally patchy even over short time scales and were unevenly distributed in vertical profiles. When the size classes were pooled, the depth-averaged larval concentration $\left(\# L^{-1}\right.$ ) varied by an order of magnitude or more within each 10-hour period (Fig. 3). Patches of Crepidula spp. and Anachis spp. generally coincided, whereas N. obsoletus were most abundant when the other two taxa were scarce or absent. $N$. obsoletus larvae were more concentrated near the bed on 27 July but not on 29 July, whereas Anachis spp. and Crepidula spp. were more concentrated at mid-depth (Fig. 4). These uneven larval 

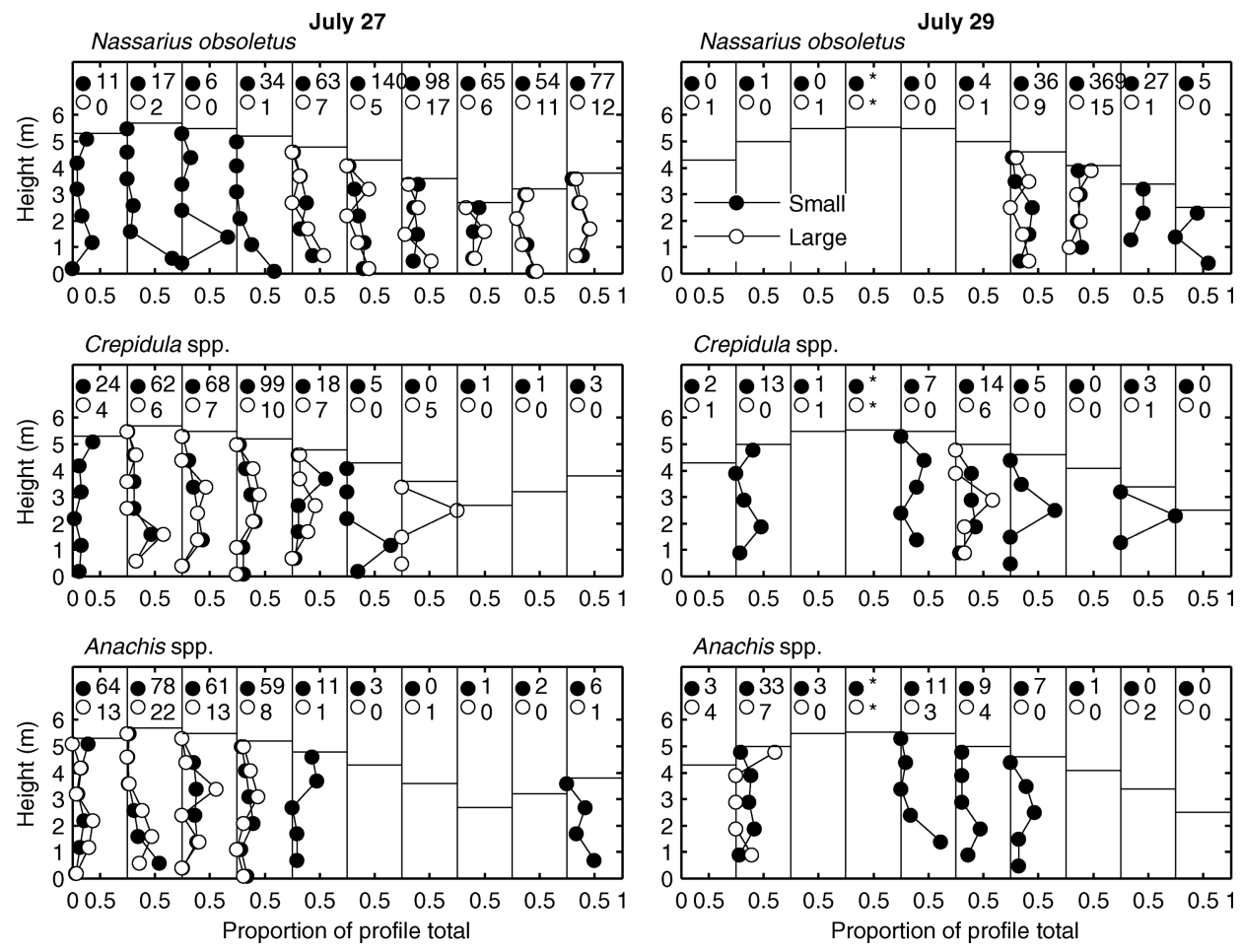

Figure 4. Ten-hour series (from 07:30 to 16:30) of vertical concentration profiles of Nassarius obsoletus (upper), Crepidula spp. (middle), and Anachis spp. (lower) larvae in large (०) and small (•) size fractions for 27 July (left) and 29 July (right). Larval concentrations shown as proportion of profile total, with totals indicated above each profile. Horizontal lines indicate water depth during sample collection. Profiles with fewer larvae than samples are not plotted and asterisks indicate profiles discarded due to slight stratification.

distributions probably are due to larval behavior, because the water column was well mixed; except at slack tides the average mixing time $H^{2} / \mathrm{K}$ was less than an hour. Under these conditions neutrally buoyant particles would quickly reach and maintain an even vertical distribution. Non-zero larval velocities would be difficult to estimate based on raw data, but the maximum likelihood analysis (see Section c) enabled us to estimate larval responses to their environment and to test hypotheses about these behaviors.

\section{c. Larval behavior}

We estimated the larval velocity as a function of environmental cues by fitting a behavioral-physical model to the observed vertical distributions of larvae in the field. Maximum-likelihood estimates indicate that all larval groups responded to a combination of turbulence and temperature cues with the exception of large $N$. obsoletus, which responded only to turbulence (Table 2). For convenience we present the responses to turbulence first, 
0
0
0
0
0
0
0
0
0
0
0
0
0
0
0
0
0
0
0
0
0
0
0
0

ㅎㅎㅇㅎㅇ용

万人

Т

o 0 i ñi

¿ब

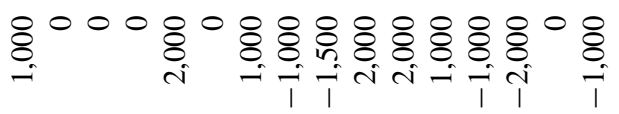

จ =

(1) 0 o

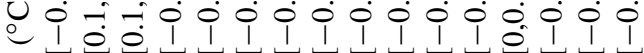

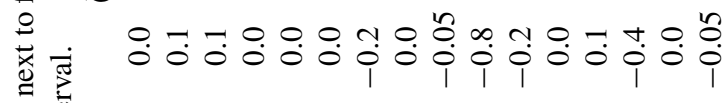

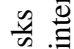

选

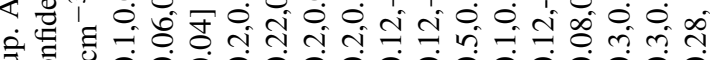

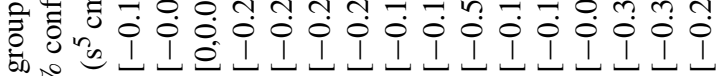

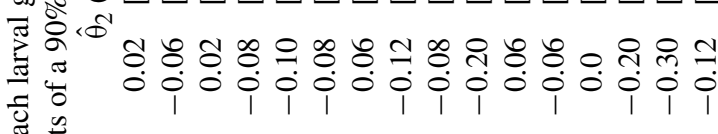

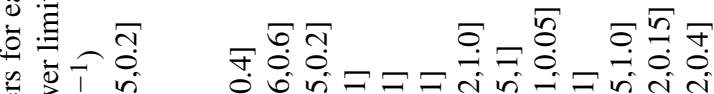

屯ै

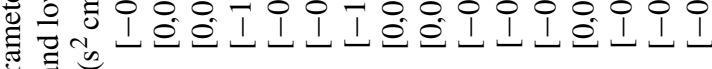

总

帘

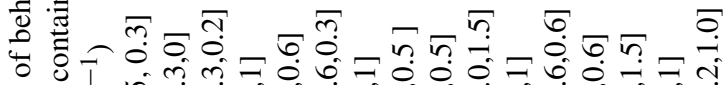

थै क ñ

近

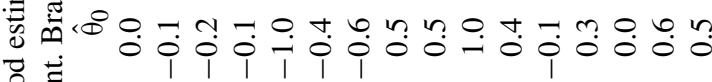

ठ

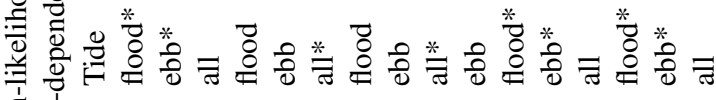

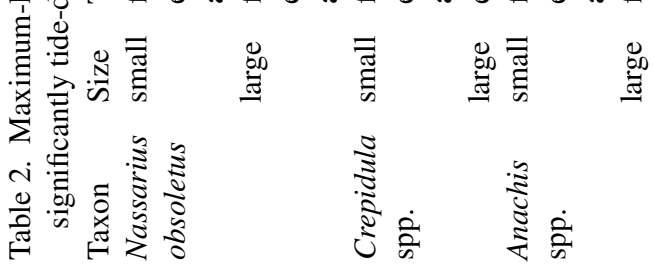


Table 3. Statistics for likelihood ratio hypothesis tests of behavioral differences between groups. Large Crepidula spp. larvae were too sparse on flood tides to analyze. Asterisks indicate significant differences $(\alpha=0.05)$.

A. $H_{1}$ : Pair-wise comparisons between genera

ebb

Group

N. obsoletus vs.

Crepidula spp.

Small

Large

N. obsoletus vs.

Anachis spp.

Small

Large

Crepidula spp.vs.

Anachis spp.

Small

Large

$88.20<0.001^{*}$

0.16

$\begin{array}{cc}39.67 & <0.001^{*} \\ 0.37 & 0.99\end{array}$

$36.47<0.001^{*}$

11.47

$0.04^{*}$

30.20

0.10

$<0.001^{*}$

1.00

B. $H_{2}$ : Small vs. Large size fractions

13.76

3.39

$0.02 *$

53.19

$<0.001^{*}$

0.64

12.52

$0.03^{*}$

\section{ebb}

Group

N. obsoletus

Crepidula spp.

$\chi^{2} \quad P$

Anachis spp.

$$
50.65
$$

$<0.001^{*}$

14.12

$0.01^{*}$

28.94

$<0.001^{*}$

C. $H_{3}$ : Ebb vs. Flood tide samples

small

Group

N. obsoletus

Crepidula spp.

Anachis spp.

$\begin{array}{cc}\chi^{2} & P \\ 29.89 & <0.001^{*} \\ 10.33 & 0.07 \\ 64.61 & <0.001^{*}\end{array}$

$31.62<0.001^{*}$

$-.-$

flood

$\chi^{2} \quad P$

$19.00<0.01^{*}$

$-.-$

32.15

$-.-$

$<0.001^{*}$

large

$x^{2}$

2.68

$-.-$

12.81

$-.-$

$0.03 *$
121.79

0.62

$$
\begin{gathered}
<0.001^{*} \\
0.34
\end{gathered}
$$

all

$x^{2}$

68.50

$-.-$

73.70

all

$x^{2}$

33.72

$-.-$

64.81

$P$

$<0.001^{*}$

$-.-$

$<0.001^{*}$

\section{$P$}

$<0.001^{*}$

$-.-$

$<0.001^{*}$

followed by the responses to temperature and temperature gradient. We discuss behavior estimates for both ebb and flood tides except where there was no significant tide-dependence (small Crepidula spp. and large N. obsoletus; Table 3).

Responses to turbulence. Most larval groups responded to turbulence by sinking in calm water and remaining nearly neutrally buoyant or swimming up in strong turbulence (Fig. 5). The exceptions were $N$. obsoletus larvae; on flood tides, small larvae swam up in calmer water and had little or no response to the highest dissipation rates. Large $N$. obsoletus larvae had near-zero velocities in moderate turbulence $\left(\varepsilon \approx 10^{-2.8}\right.$ to $10^{-1.6} \mathrm{~cm}^{2} \mathrm{~s}^{-3}$ ), but had a progressively greater sinking response in stronger turbulence $\left(\varepsilon>10^{-1.6} \mathrm{~cm}^{2} \mathrm{~s}^{-3}\right)$. For Crepidula spp., both small and large larvae sank in calmer water and swam up in stronger turbulence $\left(\varepsilon>10^{-2.0} \mathrm{~cm}^{2} \mathrm{~s}^{-3}\right.$ for small larvae, $\varepsilon>10^{-0.9} \mathrm{~cm}^{2} \mathrm{~s}^{-3}$ for large larvae). Likewise for Anachis spp. larvae, the response to turbulence contributed upward velocities 

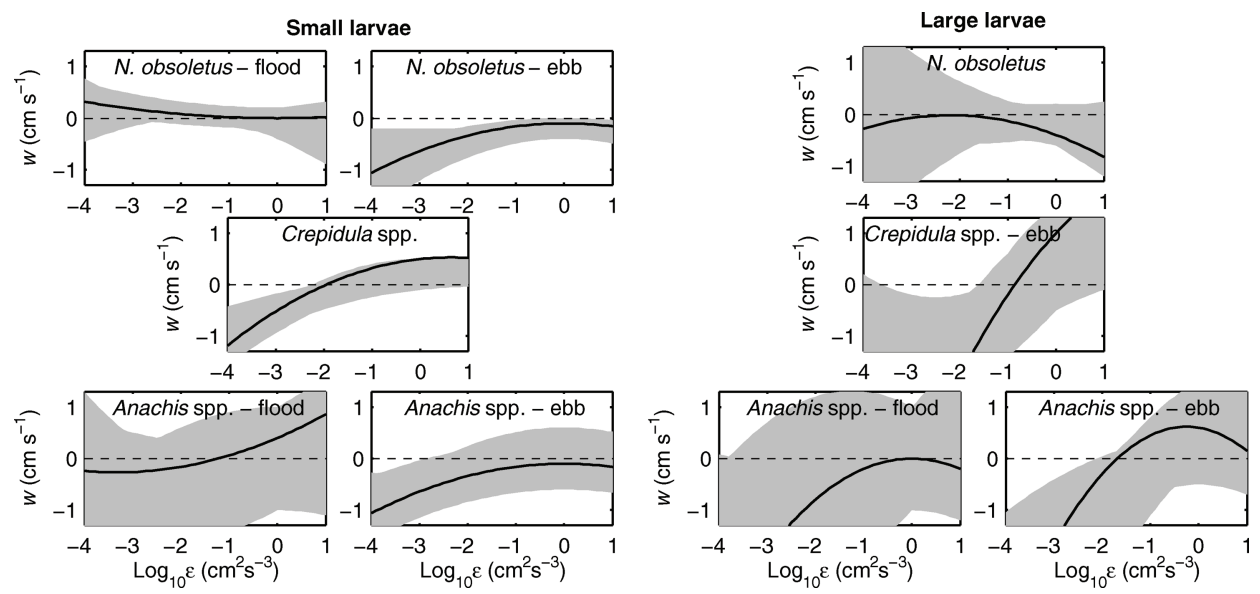

Figure 5. Turbulence-dependent component of larval velocity, shown as $w$ vs. dissipation rate $\varepsilon$ for small and large size classes. Results are presented for both ebb and flood tides if behaviors were significantly tide-dependent. Solid lines are MLE's, dotted lines indicate neutral buoyancy, and shading indicates $90 \%$ prediction interval for turbulence response $\left(\hat{\theta}_{1}, \hat{\theta}_{2}\right.$, and $\left.\hat{\theta}_{3}\right)$.

in strong turbulence for small larvae on ebb tides $\left(\varepsilon>10^{-1.2} \mathrm{~cm}^{2} \mathrm{~s}^{-3}\right)$ and large larvae on flood tides $\left(\varepsilon>10^{-1.7} \mathrm{~cm}^{2} \mathrm{~s}^{-3}\right)$. On reverse tides the response to turbulence always contributed downward velocities. Some parameter estimates contained large uncertainties. Based on the prediction intervals, for example, responses to turbulence are fairly ambiguous for some groups, particularly Anachis spp. larvae on flood tides.

Responses to temperature and temperature gradient. All groups except large N. obsoletus had some response to temperature or temperature gradient (Table 2, Fig. 6). For small $N$. obsoletus larvae, these combined responses would contribute downward movement during flood and early ebb tides and upward movement just before low tide. Temperature responses of small Crepidula spp. larvae would contribute some downward movement during ebb and low tides and upward movement during flood and high tides. Small Anachis spp. larvae would have an added downward movement during early flood tide and upward movement during the rest of the tidal cycle. Large Crepidula spp. larvae were only observed on ebb tides; temperature responses would contribute upward movement on early ebb and downward movement during late ebb. Responses of large Anachis spp. larvae would contribute to sinking just after low tide and upward movement during most of flood tide. Based on the prediction intervals for $w$, the magnitude of the response had some uncertainty, particularly for Anachis spp. and large Crepidula spp. larvae, but the direction of movement was often unequivocal.

Overall behavior. The maximum-likelihood estimates $\hat{\Theta}$ are the parameters most likely to have produced the observed larval distributions, given the behavior model. Because the 

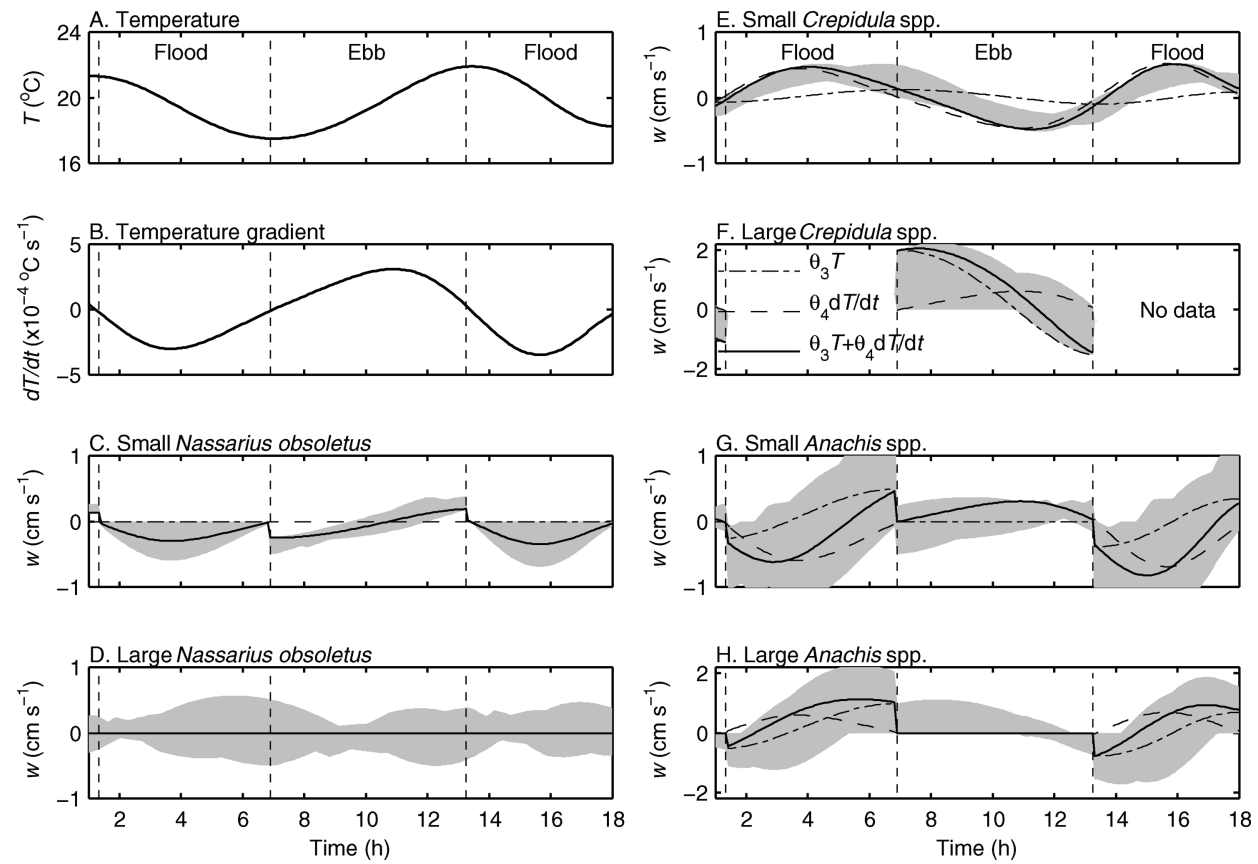

Figure 6. Temperature, temperature gradient, and components of larval velocity dependent on these cues, shown as $w$ vs. time for small and large size classes. Responses to temperature (dash-dot line) and temperature gradient (dashed line) shown separately and combined (solid line). Shading indicates $90 \%$ prediction interval for combined temperature response $\left(\hat{\theta}_{3}\right.$ and $\left.\hat{\theta}_{4}\right)$.

parameters are fit over all profiles at once, however, the model fit was poor for some profiles (Figs. 7 and 8). The fits generally were worst for profiles that had too few larvae to include in the analysis and best for profiles that included many samples with many larvae.

The overall estimates of $w$ (Eq. 5) showed different patterns of behavior between size classes and among taxa (Fig. 9). N. obsoletus of both size classes were sinking most of the time, but small larvae swam up during slack tides. Crepidula spp. and Anachis spp. behaved differently. Small larvae swam up on flood tides and near the bottom during ebb tides, but sank at high tides and in the upper water column during most of the ebb. Large larvae swam up near the bottom during peak flood and ebb tides but sank near the surface throughout most of the tidal cycle. Behaviors of small larvae were more tidally asymmetric than those of large larvae.

i. Hypothesis tests. Likelihood ratio tests showed that behaviors usually differed between taxa, with the exception of all comparisons involving large Crepidula spp. larvae (Table 3A). Large Crepidula spp. were the least abundant group; their behavior estimates are based on only 17 larvae spread over two profiles. The scarcity of these larvae may have contributed 

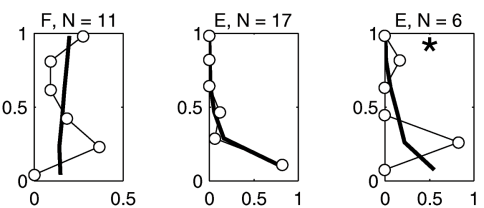

\section{Nassarius obsoletus}
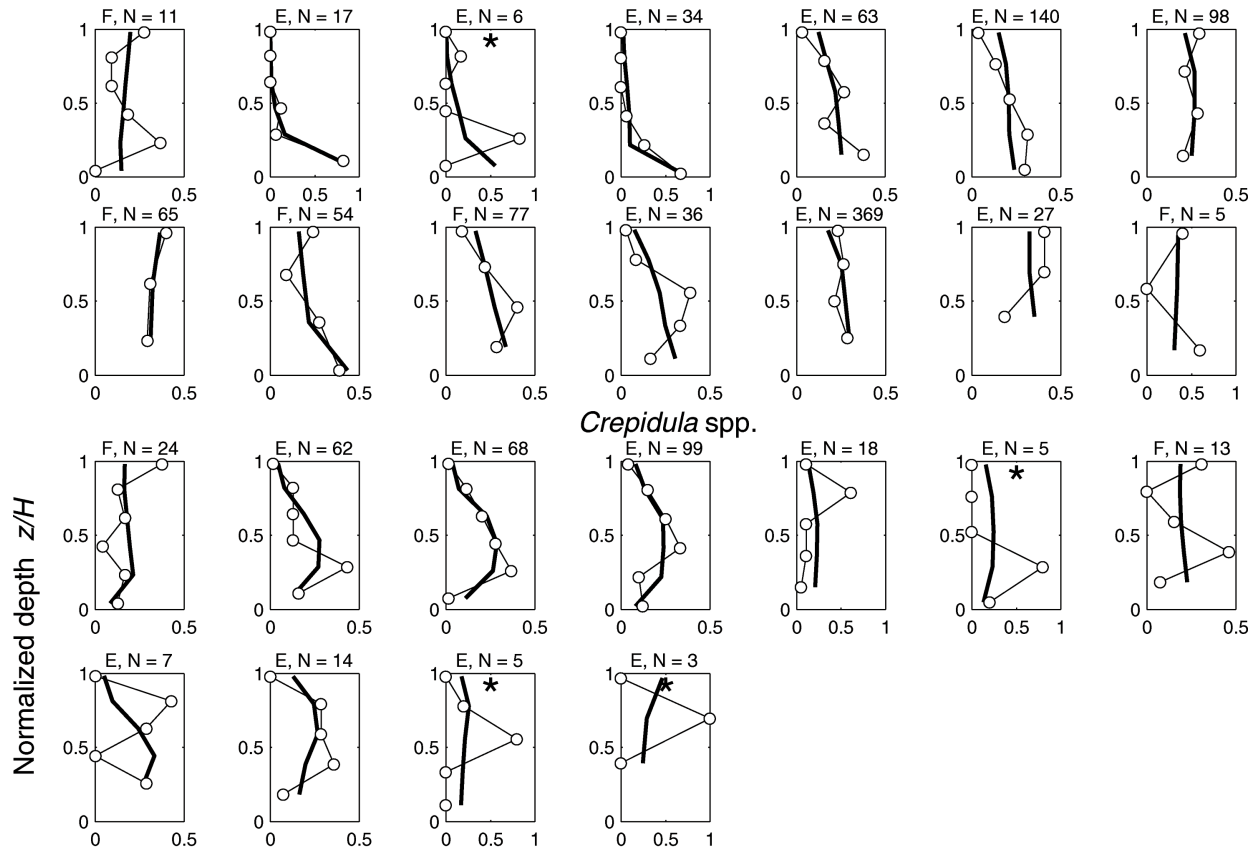

Crepidula spp.
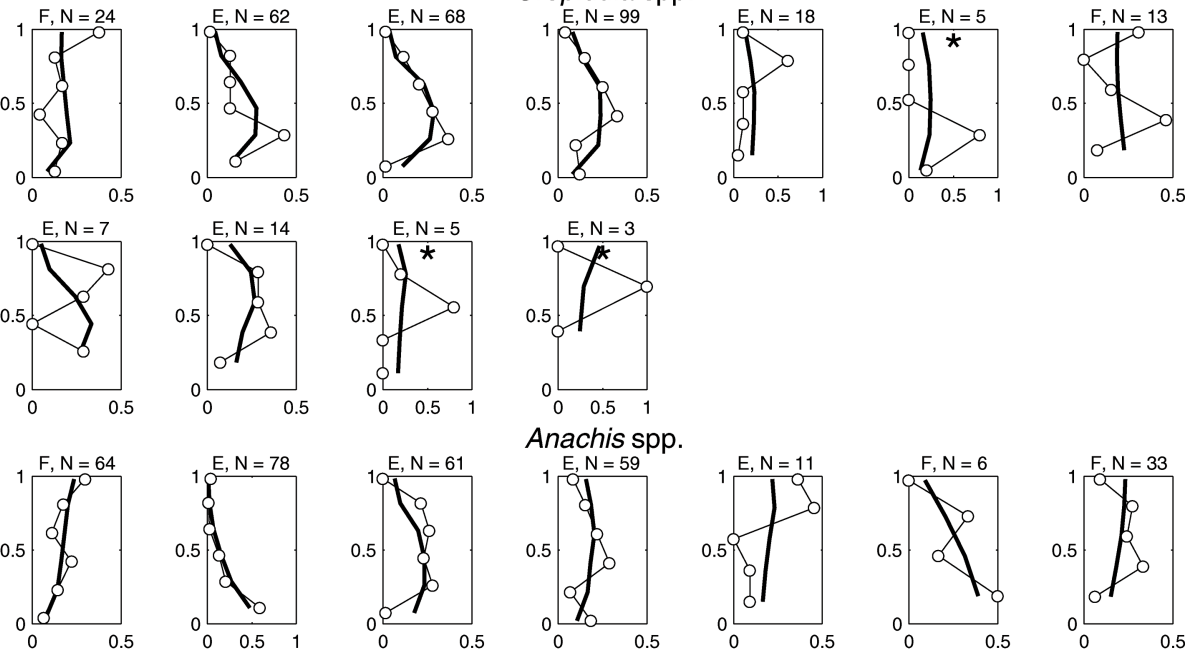

Anachis spp.
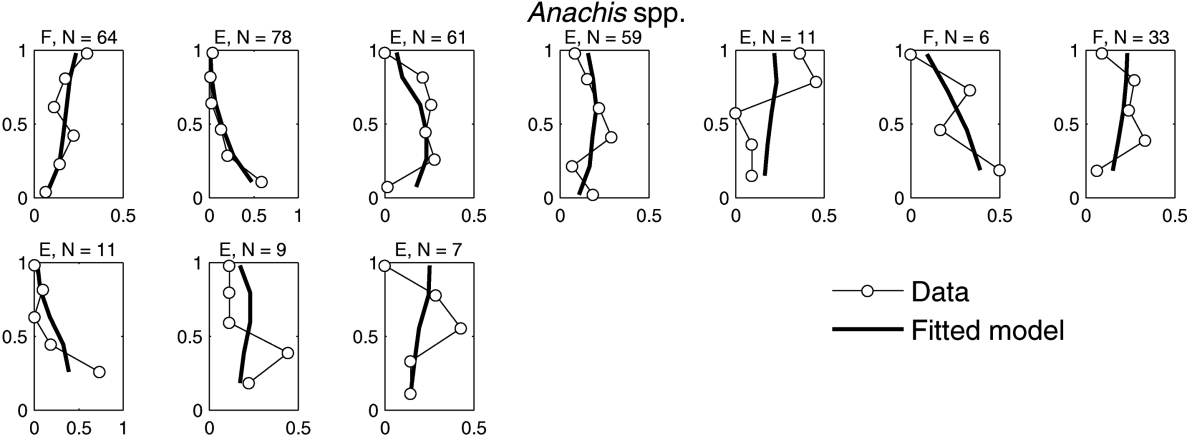

—- Data

Fitted model

Proportion of profile total

Figure 7. Measured and modeled vertical concentration distributions of small larvae. Larval concentrations in each sample shown as proportion of profile total. Circles indicate measured concentrations, solid lines indicate ML estimates. Asterisks indicate profiles excluded from behavior analysis because they had too few larvae. Tidal stage (abbreviated "E" for ebb and "F" for flood) and total number of larvae indicated above each panel.

to the lack of significance in between-taxon comparisons. Although behaviors of large Crepidula spp. were statistically similar to those of the other two taxa, the variation in larval velocity shows a greater affinity between Crepidula spp. and Anachis spp. than between Crepidula spp. and N. obsoletus (Fig. 9). For all three taxa, behaviors of small and large 

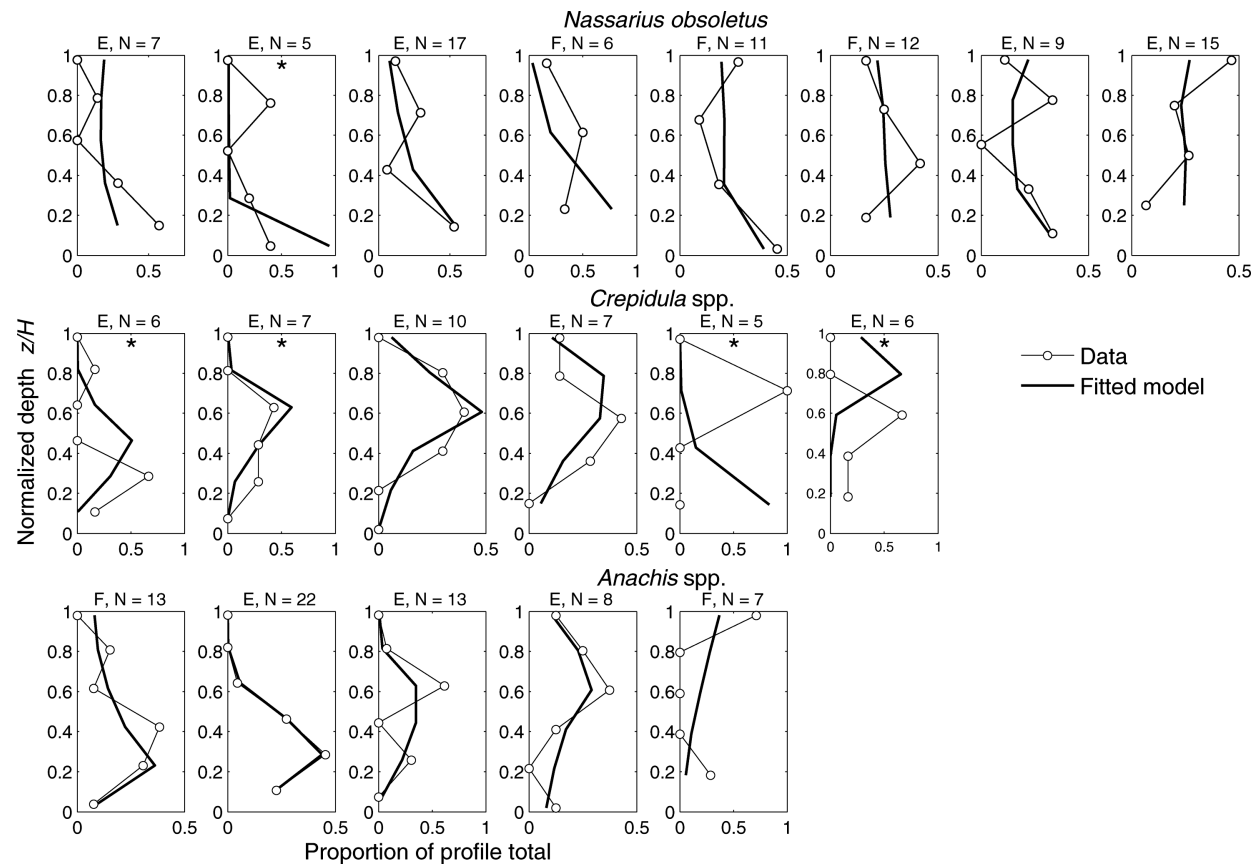

Figure 8. Measured and modeled vertical concentration distributions of large larvae. Larval concentrations in each sample shown as proportion of profile total. Circles indicate measured concentrations, solid lines indicate ML estimates. Asterisks indicate profiles excluded from behavior analysis because they had too few larvae. Tidal stage (abbreviated "E" for ebb and "F" for flood) and total number of larvae indicated above each panel.

larvae were different (Table 3B). Flood and ebb tide behaviors were statistically similar for small Crepidula spp. and large N. obsoletus but different for other groups (Table 3C).

ii. Contributions of different responses to overall behavior. The estimated response weights show that of the three physical cues in our behavior model, turbulence was the most important (Fig. 10). Small N. obsoletus larvae were the only exception; they were most responsive to the temperature gradient, followed by turbulence and then temperature. Large N. obsoletus responded only to turbulence, but a large component of their behavior was due to the constant term in Eq. 5. This result suggests a potential bias contributed by larval responses to some unaccounted-for cue (see Discussion). The beach snails, Crepidula spp. and Anachis spp., shared similar cue hierarchies. For small larvae, the response to temperature gradient contributed nearly as much to larval velocity as did the response to turbulence, but the temperature response was negligible. In contrast, large larvae were more responsive to temperature and less responsive to temperature gradient. For all taxa, the response to turbulence made a greater relative contribution to behavior for large larvae than for small larvae. 

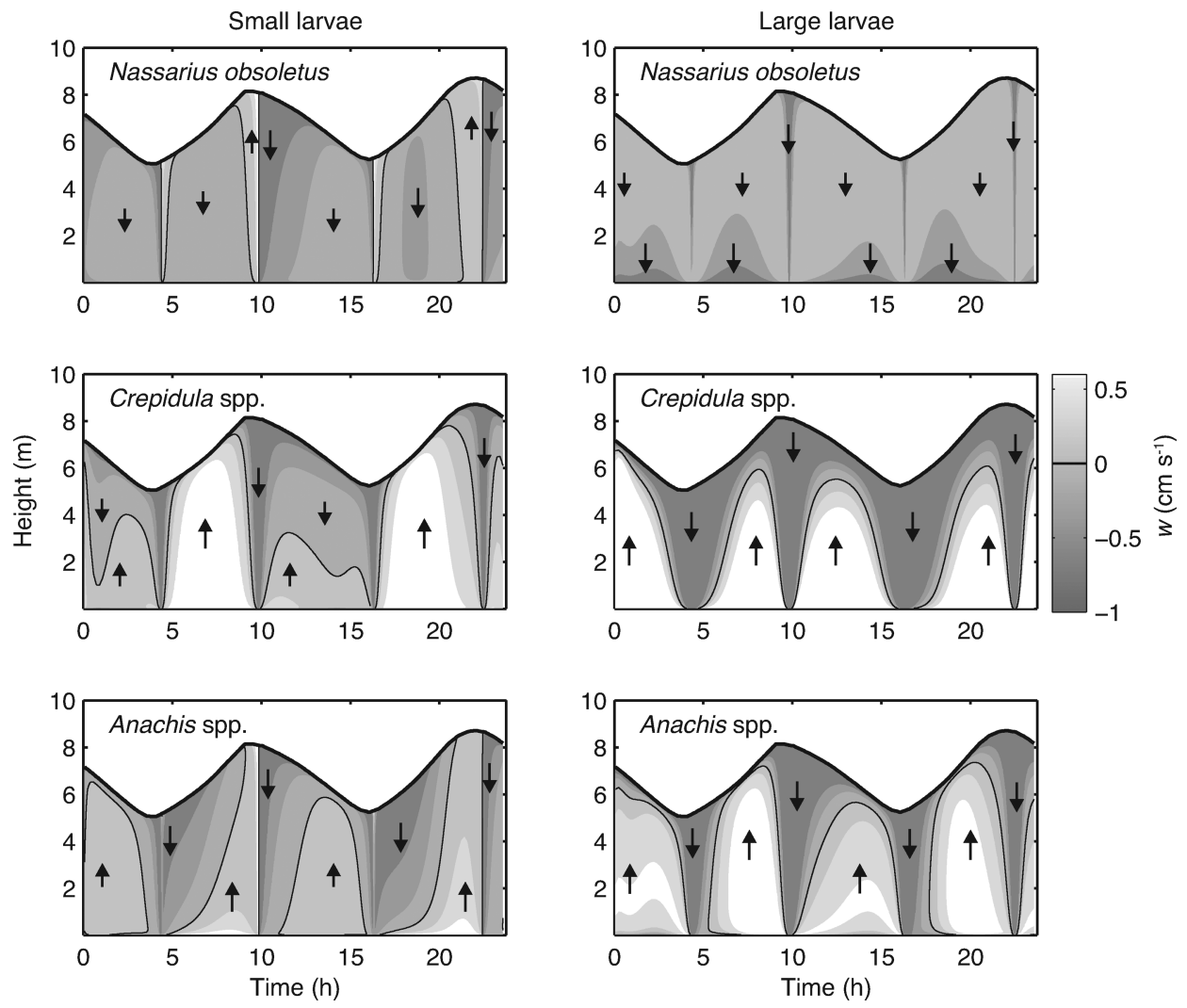

Figure 9. Predicted spatiotemporal variation in larval velocity $w$ for small and large larvae over a tidal cycle at Barnstable Harbor. Results are MLE's for Eq. 5. Arrows indicate direction of movement; color bar indicates velocity; solid contour indicates $w=0 \mathrm{~cm} \mathrm{~s}^{-1}$.

\section{Discussion}

Our analysis suggests that complex environmental signals induce strikingly different, taxon-specific responses in larvae from muddy inlets ( $N$. obsoletus) and exposed beach (Crepidula spp. and Anachis spp.) habitats. Behavior estimates also differed between size classes for all taxa and between flood and ebb tides for some groups (Table 3). These differences raise the question of what ecological forces drive behavioral adaptations. Larvae have simple needs: to eat, to avoid being eaten, and to settle in a survivable habitat. We suspect that settlement into tidal inlets would have unequal consequences for mud snails and beach snails. The location of settlement has implications for adult fitness and may be a powerful mechanism of selection for behaviors that enhance larval transport into specific habitat types. As described in the next section, our results imply that responses to turbulence and temperature may aid larvae in discriminating among different coastal environments. 

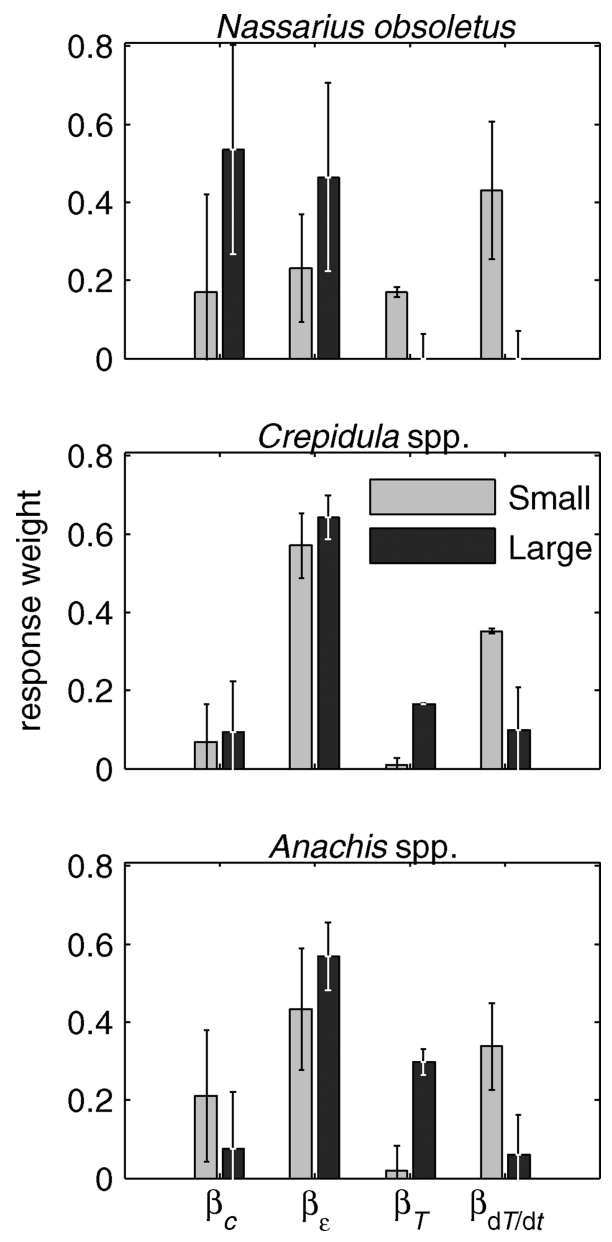

Figure 10. Response weights representing time- and space-averaged fraction of overall larval velocity (Eq. 5.) contributed by constant behavior $\beta_{c}$ and by responses to dissipation $\beta_{\varepsilon}$, temperature $\beta_{T}$, and temperature gradient $\beta_{d T / d t}$. Error bars $=$ one SD of response weights calculated from bootstrap estimates $\hat{\Theta}^{\prime}$.

\section{a. Effects of larval behavior on export and retention}

Intertidal mud snail larvae in Barnstable Harbor had behaviors that would contribute to their retention in the harbor near prime adult habitats. Small N. obsoletus larvae sank most of the time but avoided settling on the bottom during slack water, probably because mud snail larvae in this size range (200 to $425 \mu \mathrm{m}$ ) are incapable of metamorphosis (Scheltema, 1967). Large mud snail larvae appeared to seek the bottom both during slack tides and in strong turbulence, and they would escape the faster-moving surface currents. By sinking during peak tides, both small and large larvae would concentrate near the bed where currents 
are slower, effectively minimizing transport and lengthening retention time in the harbor. Turbulence-induced sinking by later-stage larvae would also enhance settlement. Larvae concentrated near the bed would have frequent contact with the sediment and should have more settlement opportunities than larvae with no strong sinking behaviors (Fuchs et al., 2007). Behaviors of mud-snail larvae are well-suited for overcoming the hydrodynamic barriers to larval retention and settlement in this energetic coastal inlet.

Unlike the mud snails, Crepidula spp. and Anachis spp. larvae avoided the bottom by swimming up during flood and ebb tides; by moving into faster surface currents, these larvae would be exported more quickly to Cape Cod Bay. Rapid export would make beach snail larvae less likely than mud snail larvae to settle within the harbor, despite the similar time-averaged abundances of all groups in the plankton. Adult snails of Crepidula spp. and Anachis spp. inhabit shallow, sandy to gravelly substrates along open coastlines. These larvae may reduce their mortality and improve their overall settlement success by spending less time in this muddy channel with no favorable habitats. Yet if beach snails have behaviors leading to transport away from turbulent tidal zones, it is unclear how these snails would return to suitable habitats along the coast.

It is difficult to predict how the estimated behaviors will affect larval dispersal in general, because flows outside the harbor are more complex than those in the Barnstable channel. Features such as internal tidal waves and surface gravity waves are prevalent in coastal currents, and we can only speculate on how these will affect larval transport. Internal waves are a regular feature of Massachusetts bay in late summer when the water column is stratified (Haury et al., 1979; Scotti and Pineda, 2004; Butman et al., 2006). The fronts of the passing waves are characterized by strong downwelling flow (Scotti and Pineda, 2004; Butman et al., 2006) and elevated turbulence with $\varepsilon \approx 10^{-3}$ to $10^{-1} \mathrm{~cm}^{2} \mathrm{~s}^{-3}$ (Sandstrom and Oakey, 1995; Scotti and Pineda, 2004). Models suggest that larvae can accumulate in fronts and be transported shoreward only if they swim upward (Helfrich and Pineda, 2003; Scotti and Pineda, 2007). Based on our behavior estimates, Crepidula spp. and Anachis spp. larvae would swim up in response to low subthermocline temperatures $\left(<20^{\circ} \mathrm{C}\right)$ and stronger turbulence associated with passing internal waves. These responses could give beach snail larvae the positive vertical velocities needed to become concentrated in internal wave fronts and propagate towards beaches along the Massachusetts coast.

Internal wave fronts should transport beach snail larvae more effectively than mud snail larvae, because large $N$. obsoletus larvae are unlikely to swim up in the turbulence associated with passing fronts. The most energetic internal wave fronts could even induce mud snail larvae to sink into subthermocline currents moving offshore. Although this behavior has no obvious benefit, one study proposes that sinking larvae can still be carried shoreward by asymmetric tidal mixing (Pringle and Franks, 2001). Our results suggest that the behavior of mud snail larvae could discourage shoreward transport in fronts but encourage retention near good habitats in energetic coastal inlets. In contrast, behaviors of beach snail larvae could discourage settlement in inhospitable muddy inlets but encourage the delivery of larvae by internal wave fronts to straight coastlines and beaches. 
Dispersal may also be affected by surface gravity waves. Although waves were minimal in Barnstable Harbor during our study, they are widespread in coastal flows where larvae disperse. Surface waves are oscillatory flows that can increase larval vertical motion (Koehl and Reidenbach, 2007) and increase transport distances through Stokes drift (Monismith and Fong, 2004). Breaking waves probably affect larval behavior more directly, because dissipation rates can be orders of magnitude higher under breaking waves than under nonbreaking ones (Agrawal et al., 1992). By our estimates, an order-of-magnitude increase in $\varepsilon$ can induce changes in larval velocity of several $\mathrm{mm} \mathrm{s}^{-1}$ (Fig. 5). Beach snail (Anachis spp. and Crepidula spp.) larvae generally switch from sinking in calm water to swimming in dissipation rates of $10^{-2}$ to $10^{-1} \mathrm{~cm}^{2} \mathrm{~s}^{-3}$. This range of $\varepsilon$ has rarely been observed in shelf waters except under breaking waves (Drennan et al., 1996; Gerbi et al., 2009). By swimming upward under breaking waves, beach snail larvae potentially could be transported farther during strong wind events.

These speculations about behavioral effects on dispersal are necessarily qualitative. A more quantitative treatment will require a 3-dimensional model that incorporates both physics and larval behavior. We developed the present behavior model as a first step towards accounting for larval responses to complex environments.

\section{b. Cue hierarchies}

Of the three cues included in our model, turbulence was the dominant behavioral cue for nearly all groups and contributed substantially to between-taxon differences in overall behavior. The cue hierarchy is a relative one that would be adjusted proportionally if our analysis included other variables that influenced behavior. Yet responses to turbulence appear to be key behaviors for coastal gastropods, even under conditions where other potential cues are widely variable. These behaviors will affect the export or retention of larvae in coastal zones and could be important for population dynamics.

Although turbulence was the dominant cue, temperature also influenced large Crepidula spp. and Anachis spp. larvae, which consistently swam up in cooler water $\left(<20^{\circ} \mathrm{C}\right)$ and sank in warmer water. Swimming up in cold water could aid larval transport in shorewardmoving fronts. Sinking in warmer water could also help larvae concentrate nearer the bottom in shallow coastal regions, particularly during slack tides when dissipation rates are low. Unlike large larvae, small larvae reacted strongly to temperature gradient, but the responses were diverse and difficult to explain. This cue changes sign with the reversing tides and could be used by larvae to tune their behavior to the direction of flow in the channel. The actual sensitivity to $d T / d t$ was surprising, however, because the maximum observed temperature gradient was comparable to the minimum temperature changes that cause estuarine crab larvae to change their behavior $\left(1.2\right.$ to $4.010^{-3}{ }^{\circ} \mathrm{C} \mathrm{s}^{-1}$; Forward, 1990). Although temperature would be a useful navigational cue, the estimated responses to temperature gradient were perplexing and may be a byproduct of an imperfect model. 
Table 4. Coefficient of determination for linear regression of physical variables. No regressions were significant at $\alpha=0.05$.

Independent variable

$\log _{10} \varepsilon\left(\mathrm{cm}^{2} \mathrm{~s}^{-3}\right)$

$\log _{10} \varepsilon\left(\mathrm{cm}^{2} \mathrm{~s}^{-3}\right)$

$\log _{10} \varepsilon\left(\mathrm{cm}^{2} \mathrm{~s}^{-3}\right)$

$T\left({ }^{\circ} \mathrm{C}\right)$

$T\left({ }^{\circ} \mathrm{C}\right)$

$T\left({ }^{\circ} \mathrm{C}\right)$

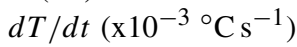

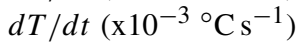

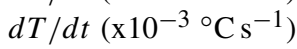

Dependent variable

$R^{2}$

$T\left({ }^{\circ} \mathrm{C}\right)$

0.12

$P$ (bar)

$\log _{10} I_{z}\left(\mathrm{~W} \mathrm{~m}^{-2}\right)$

$S$

$P$ (bar)

$\log _{10} I_{z}\left(\mathrm{~W} \mathrm{~m}^{-2}\right)$

$d S / d t\left(\mathrm{x}_{10}^{-4} \mathrm{~s}^{-1}\right)$

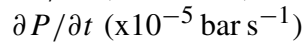

$\log _{10} \varepsilon\left(\mathrm{cm}^{2} \mathrm{~s}^{-3}\right)$
0.12

0.07

0.45

0.08

0.07

0.54

0.55

0.02

The constant behavior component ( $\theta_{0}$ in Eq. 5) indicates whether larvae would be swimming or sinking in baseline conditions of moderately strong turbulence $\left(\varepsilon=1 \mathrm{~cm}^{2} \mathrm{~s}^{-3}\right)$ and a constant $20^{\circ} \mathrm{C}$ temperature. The constant term generally made up a small fraction ( 7 to $21 \%$ ) of the overall behavior, although for large mud snail larvae this component contributed over half of the estimated velocities (54\%; Fig. 10). This term potentially contains any biases due to larval behaviors that were omitted from the model, as discussed in the next section. Despite the environmental complexity of the field site, we estimate that responses to turbulence, temperature, and temperature gradient account for a substantial fraction (46\% to $93 \%$ ) of larval velocity. Although this study was unable to quantify responses to other potential cues, the response weights suggest that turbulence and temperature exert a large influence on larval behavior within the harbor.

\section{c. Other potential behavior cues}

Larvae may have responded to additional environmental cues such as salinity, pressure, light, and odors from the benthos. Additional behaviors would be problematic if they introduced artifacts in the behavior estimates $\hat{\Theta}$. Two types of artifacts are possible. First, if larvae respond to other environmental variables that are highly correlated with the cues in our model, then the responses to turbulence or temperature could be confounded with responses to other cues. Second, if larvae respond to other cues that are uncorrelated with the ones in our model, then the estimates $\hat{\Theta}$ could be biased. Biases are less problematic than confounding effects, because they can be roughly quantified by $\beta_{c}$, the constant-component response weight. Here we address potential artifacts due to unaccounted-for physical and chemical cues.

i. Physical cues. We estimated the correlations among turbulence, temperature, temperature gradient, salinity, salinity gradient, pressure, pressure gradient, and irradiance using linear regression (Table 4). Pressure was converted from depth, and irradiance was estimated using the Beer-Lambert law $I_{z}=I_{o} \exp \left(-k_{D} z\right)$, where $I_{z}$ is the irradiance at depth $z$, 
$I_{o}$ is the surface irradiance, and $k_{D}$ is the diffuse attenuation coefficient. For $I_{o}$ we used monthly-averaged solar radiation data for July 2004 from the Martha's Vineyard Coastal Observatory (www.whoi.edu/MVCO), and for attenuation we assumed a constant $k_{D}=$ $2.0 \mathrm{~m}^{-1}$ appropriate for coastal inlets (e.g., Gallegos et al., 1990). The correlations among most of the accounted-for and unaccounted-for behavioral cues were low (Table 4), but there were high correlations between temperature and salinity, the gradients of temperature and salinity, and the gradients of temperature and pressure.

Despite the correlations between salinity and temperature, salinity and its gradient probably had little influence on larval behavior. The harbor was generally euhaline with salinity of 30 to 31 and a maximum salinity gradient of $7.1 \times 10^{-5} \mathrm{~s}^{-1}$. The measured salinity gradients were well below the reported thresholds for altering the behavior of crab larvae $\left(2.8 \times 10^{-4}\right.$ to $1.3 \times 10^{-3} \mathrm{~s}^{-1}$; Forward, 1989; Tankersley et al., 1995). Absolute changes in salinity can also affect larval behavior, but their effects on larval velocity are small and short-lived. Some bivalve larvae swim faster at higher salinity, for example, yet the swimming speeds change by only a few percent per salinity unit (Mann et al., 1991). Rapid salinity changes of 1 to 15 induce behavioral changes in estuarine mud crab larvae, but the larvae recover their previous behavior within minutes (Latz and Forward, 1977). Because salinity varied so little during our study ( $\sim 1$ unit change over $6 \mathrm{~h}$ ), larval responses to salinity probably were minimal relative to other behaviors.

The temperature and pressure gradients, $d T / d t$ and $\partial P / \partial t$, were highly correlated at any given depth but would be uncorrelated in the larval experience due to vertical mixing. Because the water column was well-mixed, temperature varied only in time, and larvae would experience a change in sign of $d T / d t$ only at slack tides. Pressure varies both in time and with a larva's vertical position, and larvae would experience high-frequency changes in the sign of the apparent $\partial P / \partial t$ as they were mixed up and down by turbulence. Although there was little correlation between $d T / d t$ and $\partial P / \partial t$ in a Lagrangian frame, large apparent pressure changes could still elicit a larval response and introduce a bias in our behavior estimates. Based on eddy turnover times, the maximum apparent $\partial P / \partial t$ would be close to threshold levels for altering behavior of crab larvae $\left(2.8 \times 10^{-5}\right.$ to $4.0 \times 10^{-4}$ bar s ${ }^{-1}$; Forward et al., 1989; Tankersley et al., 1995). Larvae that respond to pressure generally swim up when pressure increases and sink when pressure decreases. The pressure experienced by a larva depends on its trajectory through the water column, but if larvae spend equal time being mixed up and down, then any net bias due to barokinesis should be close to zero.

Another potential source of bias in the behavior estimates is larval phototaxis, because all of our samples were collected in daylight. Crepidula fornicata larvae are unresponsive to light in the laboratory (Pires and Woollacott, 1997), but no phototaxis data are available for other species in our study. Typically larvae are positively phototactic in early stages and become negatively phototactic or unresponsive to light as they grow older (e.g., Miller and Hadfield, 1986; Barile et al., 1994), although some intertidal species remain photopositive throughout the larval life span (Thorson, 1964). In this study Crepidula spp. and Anachis 
spp. larvae showed no behaviors that could be attributed to phototaxis. N. obsoletus larvae were almost always sinking. This pattern may reflect some negative phototaxis, but it would be uncharacteristic for early-stage mud snail larvae to show a negative response to light, particularly when adult $N$. obsoletus are intertidal and positively phototactic (Dimock and Parno, 1981). We expect that both light and pressure had the greatest effect, if any, on behavior of small larvae, because early-stage larvae generally have greater sensitivity to these cues (e.g., Thorson, 1964; Mann and Wolf, 1983).

ii. Chemical cues. We have no data on the nature or distribution of chemicals in the harbor, but we assume that there is a continuous flux of chemicals produced by benthic organisms. The spatio-temporal distribution of these chemicals depends on tidal stage, flow velocity, and bottom roughness. The vertically integrated concentration would increase on ebb tides as the harbor empties and decrease during flood tides as the harbor is diluted with bay water. Vertical mixing would diffuse chemicals from the benthos upward, but during slack tides these cues could remain more concentrated near the bottom (Crimaldi and Koseff, 2006). Chemical plumes are heterogeneous with discrete filaments whose structure and intensity depend on flow velocity and bottom roughness (Rahman and Webster, 2005; Crimaldi and Koseff, 2006). Both the tidal phase and the underlying substrate (e.g. bare sand or snail patches) would affect the timescale and variability of chemicals encountered by larvae. Chemical concentrations depend on production, dilution, and diffusion and should be highest at the bottom and during slack (especially low) tides. In contrast, dissipation rate is highest at the bottom during peak tides, and temperature has little depth-dependence and is highest at low tide but lowest at high tide. Given these differences in spatio-temporal distributions, chemical concentrations should be relatively uncorrelated with turbulence dissipation or temperature.

Although we can rule out chemical-related confounding effects on behavior, larval responses to chemicals still may bias the behavior estimates. We expect that any chemical cues in the harbor were more attractive for mud snails than for beach snails. Seawater conditioned in Barnstable Harbor sediment induces metamorphosis of mud snail larvae (Scheltema, 1961), and sediment-associated phytoplankton may also influence larval behavior. Some larvae, including Crepidula spp., will swim downward and settle in the presence of adult-conditioned seawater or synthetic analogs (Eyster and Pechenik, 1988; Turner et al., 1994; Browne and Zimmer, 2001). Adult Crepidula spp. and Anachis spp. are rare or absent within the harbor, but $N$. obsoletus are abundant, and $N$. obsoletus larvae may have reacted to conspecific chemicals by sinking more frequently. If competent $N$. obsoletus larvae respond to chemicals as a precursor to settlement, this could explain why the constant velocity component $\hat{\theta}_{0}$ indicated faster sinking for large larvae than for small larvae (Table 2 ).

\section{d. Data limitations}

Larval patchiness is unpredictable and was a problem in this study because the sample resolution was already limited by the labor-intensive method of plankton sampling. 
Although we found abundant gastropod larvae in our samples and could identify them to species, large larvae of the most common taxa were fairly rare. The sparseness of the data contributed to large uncertainties in some behavior estimates. The best precaution against low larval concentrations would be to sample more plankton profiles, but the time required to collect, sort, and identify samples is nontrivial.

Another alternative is remote sampling, but this is an imperfect solution for behavior studies that require species-level identification. Future studies could combine a video plankton recorder (Davis et al., 1996) with other instruments, for example, to observe larval behavior and measure physical variables simultaneously over long time periods. Unfortunately many larval identifications depend on morphological characteristics that are visible only under a microscope. Holoplankton are sometimes identified manually (Gallager et al., 2004) or automatically (Hu and Davis, 2006) from video images collected at sea, and these approaches could work for distinctive larvae. Other solutions may come from new approaches such as video holography (Sheng et al., 2006) and the use of shell birefringence patterns for identification (Tiwari and Gallager, 2003). For now, however, traditional plankton sampling is the most straightforward way to observe species-level larval distributions at sea. As we show here, larval distributions can be used to estimate behaviors even when larval swimming speeds cannot be measured directly.

\section{e. Habitat selection}

Several laboratory studies have shown that habitat selection occurs during larval settlement and reduces post-settlement mortality (e.g., Harrington et al., 2004; Larsson and Jonsson, 2006), but there has been limited evidence for habitat selection during the dispersal phase. Larval swimming behaviors do affect survivorship and community structure of sessile species, because the vertical position of larvae in the water column contributes to vertical zonation at settlement (Grosberg, 1982; Raimondi and Morse, 2000). The question is whether differences in larval swimming behavior among species or populations (e.g., Manuel et al., 1996) represent adaptations for dispersal into distinct habitats. In this study, snail larvae from intertidal estuarine and coastal habitats had markedly different responses to multiple environmental cues, suggesting that habitat selection occurs throughout development in the form of behavioral responses to coastal physical regimes. In Barnstable Harbor, larval behaviors evidently influence the availability of certain gastropod larvae for settlement and ultimately may reinforce the structure of the existing benthic community.

Acknowledgments. Fuchs designed and carried out the field work, did the analyses, and wrote the manuscript. Solow designed the analyses and contributed to manuscript preparation. Mullineaux assisted with the study design, field work, and manuscript editing.

Logistical support, instrument loans, and assistance with field work were provided by L. Davies, M. Dennet, C. DiBacco, S. Elgar, R. Geyer, M. Gould, K. Houtler, R. Jennings, L. Kalnejais, T. Klanscek, J. Lerczak, L. Levin, M. McElroy, J. Murray, D. Poehls, J. Sisson, C. Strasser, E. Terray, A. Williams, M. Workman, Millway Marina, and the Barnstable Harbormasters. 
P. Schultz and J. Thompson generously gave technical advice and deployed and recovered the current meters. We thank J. Trowbridge, S. Elgar, J. Lerczak, A. Williams, P. Orton, E. Terray, G. Gerbi and F. Fedderson for helpful discussions about turbulence measurements and analyses. M. Neubert, G. Flierl, D. Grünbaum, R. Scheltema, and S. Gallager provided constructive input on early manuscript drafts, and R. Zimmer, J. Grassle, D. Rice, and five anonymous reviewers provided comments that improved the manuscript.

This work was funded by the Woods Hole Oceanographic Institution (WHOI) Coastal Ocean Institute, the WHOI Rinehart Coastal Research Center, the National Science Foundation (NSF OCE0326734), NSF and US Office of Naval Research grants to S. Elgar and B. Raubenheimer, and the WHOI Sea Grant (National Oceanic and Atmospheric Administration, Grant No. NA16RG2273, project no. R/O-38-PD). Analyses were completed while HLF was a postdoctoral scholar at Scripps Institution of Oceanography (SIO), supported by the California Current Ecosystem Long-Term Ecological Research program (NSF OCE-0417616) and by SIO funding to P. Franks.

\section{APPENDIX}

Surface response functions fitted to physical data

Physical measurements for the study period are summarized in Figure 2. These measurements could not be used directly in the advection-diffusion model because they were discontinuous in space and time. Instead, we fitted high-order polynomial response surfaces (e.g., Box and Draper, 1987) to our measurements of eddy diffusivity, turbulence dissipation rate, temperature, and temperature gradient. The purpose of these functions was not to improve our understanding of turbulence and temperature variation, but rather to provide accurate, continuous-time representations of the environment for use in the advection-diffusion model and associated behavior model (Eqs. 4 and 5).

Before fitting the response surfaces to turbulence data, we first estimated dissipation and diffusivity in the near-bottom region where measurements were sparse. The instruments provided dissipation estimates at $z=0.78 \mathrm{~m}$ and $z=1.5$ to $H \mathrm{~m}$, and diffusivity estimates from $z=1.5$ to $H \mathrm{~m}$. We estimated the dissipation rate from $z=1.5 \mathrm{~m}$ to the bed as

$$
\left.\varepsilon_{p}(z, t)\right|_{z<1.5}=\frac{u_{*}^{3}}{\kappa z}
$$

with the assumption that turbulence production and dissipation are balanced near the bottom. We extrapolated the eddy diffusivity from $z=1.5 \mathrm{~m}$ to the bottom as

$$
\left.K_{p}(z, t)\right|_{z<1.5}=\overline{u^{\prime} w^{\prime}} / \frac{\partial U}{\partial z}=u_{*}^{2}(1-z / H) / \frac{\partial U}{\partial z},
$$

with the assumptions that the Reynolds stress $\overline{u^{\prime} w^{\prime}}$ scales with shear velocity as indicated (e.g., Nezu and Nakagawa, 1993) and the current velocity $U$ decreases linearly vs. $\ln z$ to 0 at the bed (the log law with a no-slip condition). Our best estimates of $u_{*}$ were from the ADV, but the ADV recorded bursts only every half hour and some noisy bursts were excluded. For 
Table A1. Polynomial orders of $z$ and $t$ used to fit $K$ and $\varepsilon$ to measured diffusivity $K_{p}$ and dissipation rate $\varepsilon_{p}$ for plankton sampling periods, and $R^{2}$ for model vs. data regressions of diffusivity, dissipation, shear velocity, temperature, and temperature gradient. Shear velocity $u_{*}$ was fitted with a time-dependent polynomial of 15th order. Temperature $T$ and temperature gradient $d T / d t$ were fitted with time-dependent polynomials of 12th order.

\begin{tabular}{|c|c|c|c|c|c|c|c|c|c|}
\hline sampling & \multicolumn{3}{|c|}{$K$} & \multicolumn{3}{|c|}{$\varepsilon$} & $u_{*}$ & $T$ & $d T / d t$ \\
\hline date & $z^{o}$ & $t^{o}$ & $R^{2}$ & $z^{o}$ & $t^{o}$ & $R^{2}$ & $R^{2}$ & $R^{2}$ & $R^{2}$ \\
\hline 22 July & 20 & 9 & 0.58 & 20 & 7 & 0.85 & 0.79 & 0.99 & 0.75 \\
\hline 27 July & 20 & 7 & 0.61 & 19 & 8 & 0.89 & 0.84 & 0.99 & 0.76 \\
\hline 29 July & 18 & 10 & 0.60 & 18 & 6 & 0.85 & 0.71 & 0.98 & 0.71 \\
\hline
\end{tabular}

$u_{*}$ in the estimates (Eqs. A1-A2), we fitted a smooth polynomial (15th order in time) to the ADV measurements of $u_{*}$, supplemented with $u_{*}$ from the ADCP. We combined these nearbottom model estimates of dissipation $\varepsilon_{p}$ and diffusivity $K_{p}$ with the upper water-column measurements from the ADCP. We then fitted polynomial response surfaces to the depthnormalized dissipation rate $\varepsilon_{p}$ and diffusivity $K_{p}$ on a $\log _{10}$ scale to produce the continuous functions $\varepsilon$ (Fuchs, 2005, Fig. 4-7) and $K$ (Fuchs, 2005, Fig. 4-6). For each sampling day we used the polynomial orders of $z$ and $t$ that gave the highest $R^{2}$ in a regression of model vs. data (Table A1).

Because the water column was well mixed, we treated temperature as variable only in time. We fitted smooth polynomials (12th order in time) to the temperature and temperature gradient from the ADCP to get continuous functions $T$ and $d T / d t$. The ADCP temperature data were recorded at high frequency and closely matched the vertically averaged temperature from CTD profiles.

\section{REFERENCES}

Agrawal, Y. C., E. A. Terray, M. A. Donelan, P. A. Hwang, A. J. Williams III, W. M. Drennan, K. K. Kahma, and S. A. Kitaigorodskii. 1992. Enhanced dissipation of kinetic energy beneath surface waves. Nature, 359, 219-220.

Ayers, J. C. 1959. The 1959. The hydrography of Barnstable Harbor, Oceanogr., 4, 448-462.

Barile, P. J., A. W. Stoner, and C. M. Young. 1994. Phototaxis and vertical migration of the queen conch (Strombus gigas Linne) veliger larvae. J. Exp. Biol., 183, 147-162.

Box, G. E. P. and N. R. Draper. 1987. Empirical Model-Building and Response Surfaces, John Wiley \& Sons, NY, 669 pp.

Browne, K. A. and R. K. Zimmer. 2001. Controlled field release of a waterborne chemical signal stimulates planktonic larvae to settle. Biol. Bull., 200, 87-91.

Butman, B., P. S. Alexander, A. Scotti, R. C. Beardsley, and S. P. Anderson. 2006. Large internal waves in Massachusetts Bay transport sediments offshore. Cont. Shelf Res., 26, 2029-2049.

Chia, F.-S., J. Buckland-Nicks, and C. M. Young. 1984. Locomotion of marine invertebrate larvae: A review. Can. J. Zoolog., 62, 1205-1222.

Cowen, R. K., C. B. Paris, and A. Srinivasan. 2006. Scaling of connectivity in marine populations. Science, 311, 522-527. 
Crimaldi, J. P. and J. R. Koseff. 2006. Structure of turbulent plumes from a momentumless source in a smooth bed. Environ. Fluid Mech., 6, 573-592.

Crimaldi, J. P., J. K. Thompson, J. H. Rosman, R. J. Lowe, and J. R. Koseff 2002. Hydrodynamics of larval settlement: The influence of turbulent stress events at potential recruitment sites. Limnol. Oceanogr., 47, 1137-1151.

Cronin, T. W. 1982. Estuarine retention of larvae of the crab Rhithropanopeus harrisii. Estuarine Coastal Shelf Sci., 15, 207-220.

Csanady, G. T. 1963. Turbulent diffusion of heavy particles in the atmosphere. J. Atmos. Sci., 20, 201-208.

Davis, C. S., S. M. Gallager, M. Marra, and W. K. Stewart. 1996. Rapid visualization of plankton abundance and taxonomic composition using the Video Plankton Recorder. Deep-Sea Res. II, 43, 1947-1970.

DiBacco, C., D. Sutton, and L. McConnico. 2001. Vertical migration behavior and horizontal distribution of brachyuran larvae in a low-inflow estuary: implications for bay-ocean exchange. Mar. Ecol. Prog. Ser., 217, 191-206.

Dillon, T. M. and D. R. Caldwell. 1980. The Batchelor spectrum and dissipation in the upper ocean. J. Geophys. Res., 85, 1910-1916.

Dimock, Jr., R. V. and J. R. Parno. 1981. Bi-modal sensitivity to monochromatic light by the mud snail Ilyanassa obsoleta. Mar. Behav. Physiol., 7, 291-296.

Drennan, W. M., M. A. Donelan, E. A. Terray, and K. B. Katsaros. 1996. Oceanic turbulence dissipation measurements in SWADE. J. Phys. Oceanogr., 26, 808-815.

Eckman, J. E., F. E. Werner, and T. F. Gross. 1994. Modelling some effects of behavior on larval settlement in a turbulent boundary layer. Deep-Sea Res. II, 41, 185-208.

Elgar, S., B. Raubenheimer, and R. T. Guza. 2001. Current meter performance in the surf zone. J. Atmos. Oceanic Technol., 18, 1735-1746.

Eyster, L. S. and J. A. Pechenik. 1988. Comparison of growth, respiration, and feeding of juvenile Crepidula fornicata (L.) following natural or KCl-triggered metamorphosis. J. Exp. Biol., 118, 269-279.

Fingerut, J. T., C. A. Zimmer, and R. K. Zimmer. 2003. Larval swimming overpowers turbulent mixing and facilitates transmission of a marine parasite. Ecology, 84, 2502-2515.

Forward, Jr., R. B. 1989. Behavioral responses of crustacean larvae to rates of salinity change. Biol. Bull., 176, 229-238.

1990. Behavioral responses of crustacean larvae to rates of temperature change. Biol. Bull., 178, 195-204.

Forward, Jr., R. B., C. A. Wellins, and C. U. Buswell. 1989. Behavioral responses of larvae of the crab Neopanope sayi to hydrostatic pressure. Mar. Ecol. Prog. Ser., 57, 267-277.

Fuchs, H. L. 2005. Biophysical Coupling Between Turbulence, Larval Behavior, and Larval Supply, $\mathrm{PhD}$ thesis, MIT \& Woods Hole Oceanographic Institution Joint Program.

Fuchs, H. L., L. S. Mullineaux, and A. R. Solow. 2004. Sinking behavior of gastropod larvae (Ilyanassa obsoleta) in turbulence. Limnol. Oceanogr., 49, 1937-1948.

Fuchs, H. L., M. G. Neubert, and L. S. Mullineaux. 2007. Effects of turbulence-mediated larval behavior on larval supply and settlement in tidal currents. Limnol. Oceanogr., 52, 1156-1165.

Gallager, S. M., H. Yamazaki, and C. S. Davis. 2004. Contribution of fine-scale structure and swimming behavior to formation of plankton layers on Georges Bank. Mar. Ecol. Prog. Ser., 267, 27-43.

Gallegos, C. L., D. L. Correll, and J. W. Pierce. 1990. Modeling spectral diffuse attenuation, absorption, and scattering coefficients in a turbid estuary. Limnol. Oceanogr., 35, 1486-1502.

Genin, A., J. S. Jaffe, R. Reef, C. Richter, and P. J. S. Franks. 2005. Swimming against the flow: a mechanism of zooplankton aggregation. Science, $308,860-862$. 
George, R., R. E. Flick, and R. T. Guza 1994. Observations of turbulence in the surf zone. J. Geophys. Res., 99, 801-810.

Gerbi, G. P., J. H. Trowbridge, E. A. Terray, A. J. Plueddemann, and T. Kukulka 2009. Observations of turbulence in the ocean surface boundary layer: Energetics and transport. J. Phys. Oceanogr., 39, 1077-1096.

Gerlach, G., J. Atema, M. J. Kingsford, K. P. Black, and V. Miller-Sims 2007. Smelling home can prevent dispersal of reef fish. Proc. Natl. Acad. Sci. USA, 104, 858-863.

Grant, H. L., R. W. Stewart, and A. Moilliet. 1962. Turbulence spectra from a tidal channel. J. Fluid Mech., 12, 241-263.

Grosberg, R. K. 1982. Intertidal zonation of barnacles: the influence of planktonic zonation of larvae on vertical distribution of adults. Ecology, 63, 894-899.

Gross, T. F. and A. R. M. Nowell. 1985. Spectral scaling in a tidal boundary layer. J. Phys. Oceanogr., 15, 496-508.

Guizien, K., T. Brochier, J.-C. Duchêne, B.-S. Koh, and P. Marsaleix 2006. Dispersal of Owenia fusiformis larvae by wind-driven currents: turbulence, swimming behaviour and mortality in a three-dimensional stochastic model. Mar. Ecol. Prog. Ser., 311, 47-66.

Hadfield, M.G. and M. A. R. Koehl. 2004. Rapid behavioral responses of an invertebrate larva to dissolved settlement cue. Biol. Bull., 207, 28-43.

Harrington, L., K. Fabricius, G. De'ath, and A. Negri. 2004. Recognition and selection of settlement substrata determine post-settlement survival in corals. Ecology, 85, 3428-3437.

Haury, L. R., M. G. Briscoe, and M. H. Orr. 1979. Tidally generated internal wave packets in Massachusetts Bay. Nature, 278, 312-317.

Helfrich, K. R. and J. Pineda. 2003. Accumulation of particles in propagating fronts. Limnol. Oceanogr., 48, 1509-1520.

Hidu, H. and H. H. Haskin. 1978. Swimming speeds of oyster larvae Crassostrea virginica in different salinities and temperatures. Estuaries, 1, 252-255.

$\mathrm{Hu}, \mathrm{Q}$. and C. Davis. 2006. Accurate automatic quantification of taxa-specific plankton abundance using dual classification with correlation. Mar. Ecol. Prog. Ser., 306, 51-61.

Hunt, H. L. 2005. Effects of sediment source and flow regime on clam and sediment transport. Mar. Ecol. Prog. Ser., 296, 143-153.

Hunt, H. L., D. A. McLean, and L. S. Mullineaux. 2003. Post-settlement alteration of spatial patterns of soft shell clam (Mya arenaria) recruits. Estuaries, 26, 72-81.

Jonsson, P. R., C. André, and M. Lindegarth. 1991. Swimming behaviour of marine bivalve larvae in a flume boundary-layer flow: Evidence for near-bottom confinement. Mar. Ecol. Prog. Ser., 79, $67-76$.

Kingsford, M. J., J. M. Leis, A. Shanks, K. C. Lindeman, S. G. Morgan, and J. Pineda. 2002. Sensory environments, larval abilities and local self-recruitment. B. Mar. Sci., 70S, 309-340.

Koehl, M. A. R. and M. A. Reidenbach. 2007. Swimming by microscopic organisms in ambient water flow. Exp. Fluids, 43, DOI 10.1007/s00348-007-0371-6.

Koehl, M. A. R., J. A. Strother, M. A. Reidenbach, J. R. Koseff, and M. G. Hadfield (2007. Individualbased model of larval transport to coral reefs in turbulent, wave-driven flow: behavioral responses to dissolved settlement inducer. Mar. Ecol. Prog. Ser., 335, 1-18.

Larsen, P. S. and H. U. Riisgård. 2009. Viscosity and not biological mechanisms often controls the effects of temperature on ciliary activity and swimming velocity of small aquatic organisms. J. Exp. Biol., 381, 67-73.

Larsson, A. I. and P. R. Jonsson. 2006. Barnacle larvae actively select flow environments supporting post-settlement growth and survival. Ecology, 87, 1960-1966. 
Latz, M. I. and R. B. Forward, Jr. 1977. The effect of salinity upon phototaxis and geotaxis in a larval crustacean. Biol. Bull., 153, 163-179.

Lu, Y. and R. G. Lueck. 1999a. Using a broadband ADCP in a tidal channel. Part I: Mean flow and shear. J. Atmos. Oceanic Technol., 16, 1556-1567.

1999b. Using a broadband ADCP in a tidal channel. Part II: Turbulence. J. Atmos. Oceanic Technol., 17, 1568-1579.

Mann, R., B. M. Campos, and M. W. Luckenbach. 1991. Swimming rate and responses of larvae of three mactrid bivalves to salinity discontinuities. Mar. Ecol. Prog. Ser., 68, 257-269.

Mann, R. and C. C. Wolf. 1983. Swimming behaviour of larvae of the ocean quahog Arctica islandica in response to pressure and temperature. Mar. Ecol. Prog. Ser., 13, 211-218.

Manuel, J. L., S. M. Gallager, C. M. Pearce, D. A. Manning, and R. K. O'Dor. 1996. Veligers 1996. Veligers from different populations of sea Placopecten magellanicus have different vertical migration patterns. Mar. Ecol. Prog. Ser., 142, 147-163.

McCullagh, P. and J. A. Nelder. 1989. Generalized Linear Models, CRC Press, Boca Raton, FL, 511 pp.

Metaxas, A. and M. Saunders. 2009. Quantifying the "bio-" components in biophysical models of larval transport in marine benthic invertebrates: Advances and pitfalls. Biol. Bull., 216, 257-272.

Miller, S. E. and M. G. Hadfield. 1986. Ontogeny of phototaxis and metamorphic competence in larvae of the nudibranch Phestilla sibogae Bergh (Gastropoda: Opisthobranchia). J. Exp. Biol., 97, 95-112.

Monismith, S. G. and D. A. Fong. 2004. A note on the potential transport of scalars and organisms by surface waves. Limnol. Oceanogr., 49, 1214-1217.

Mullineaux, L. S. and E. D. Garland. 1993. Larval recruitment in response to manipulated field flows. Mar. Biol., 116, 667-683.

Nezu, I. and H. Nakagawa. 1993. Turbulence in Open-Channel Flows, A. A. Balkema, Rotterdam, 293 pp.

North, E. W., Z. Schlag, R. R. Hood, M. Li, L. Zhong, T. Gross, and V. S. Kennedy 2008. Vertical swimming behavior influences the dispersal of simulated oyster larvae in a coupled particle-tracking and hydrodynamic model of Chesapeake Bay. Mar. Ecol. Prog. Ser., 359, 99-115.

Oakey, N. S. and J. A. Elliott. 1982. Dissipation within the surface mixed layer. J. Phys. Oceanogr., $12,171-185$.

Pawlik, J. P. 1992. Chemical 1992. Chemical ecology of the settlement of benthic Mar. Biol., 30, 273-335.

Pawlik, J. P. and C. A. Butman. 1993. Settlement of a marine tube worm as a function of current velocity: Interacting effects of hydrodynamics and behavior. Limnol. Oceanogr., 38, 1730-1740.

Pineda, J. 1999. Circulation and larval distribution in internal tidal bore warm fronts. Limnol. Oceanogr., 44, 1400-1414.

Pires, A. and R. M. Woollacott. 1997. Serotonin and dopamine have opposite effects on phototaxis in larvae of the bryozoan Bugula neritina. Biol. Bull., 192, 399-402.

Podolsky, R. D. and R. B. Emlet. 1993. Separating the effects of temperature and viscosity on swimming and water movement by sand dollar larvae (Dendraster excentricus). J. Exp. Mar. Biol. Ecol., 176, 207-221.

Pringle, J. M. and P. J. S. Franks. 2001. Asymmetric mixing transport: A horizontal transport mechanism for sinking plankton. Limnol. Oceanogr., 46, 381-391.

Rahman, S. and D. R. Webster. 2005. The effect of bed roughness on scalar fluctuations in turbulent boundary layers. Exp. Fluids, 38, 372-384.

Raimondi, P. T. and A. N. C. Morse. 2000. The consequences of complex larval behavior in a coral. Ecology, 81, 3193-3211. 
Rippeth, T. P., E. Williams, and J. H. Simpson. 2002. Reynolds stress and turbulent energy production in a tidal channel. J. Phys. Oceanogr., 32, 1242-1251.

Ross, O. N. and J. Sharples. 2004. Recipe for 1-D Lagrangian particle tracking models in space-varying diffusivity. Limnol. Oceanogr.-Meth., 2, 289-302.

Sanders, H. L., E. M. Goudsmit, E. L. Mills, and G. E. Hampson. 1962. A study of the intertidal fauna of Barnstable Harbor, Massachusetts. Limnol. Oceanogr., 7, 63-79.

Sandstrom, H. and N. S. Oakey. 1995. Dissipation in internal tides and solitary waves. J. Phys. Oceanogr., 25, 604-614.

Scheltema, A. 1969. Pelagic larvae of New England gastropods: IV. Anachis translirata and Anachis avara (Columbellidae, Prosobranchia). Vie Milieu A Biol. Mar., 1-A, 94-104.

Scheltema, R. S. 1961. Metamorphosis of the veliger larvae of Nassarius obsoletus (Gastropoda) in response to bottom sediment. Biol. Bull., 120, 92-109.

— 1962. Pelagic larvae of New England intertidal gastropods. I. Nassarius obsoletus Say and Nassarius vibex Say. T. Am. Microsc. Soc., 81, 1-11.

1967. The relationship of temperature to the larval development of Nassarius obsoletus (Gastropoda). Biol. Bull., 132, 253-265.

Scotti, A. and J. Pineda. 2004. Observations of very large and steep internal waves of elevation near the Massachusetts coast. Geophys. Res. Lett., 31, doi:10.1029/2004GL021052.

2007. Plankton accumulation and transport in propagating nonlinear internal fronts. J. Mar. Res., $65,117-145$.

Sheng, J., E. Malkiel, and J. Katz. 2006. Digital holographic microscope for measuring threedimensional particle distributions and motions. Appl. Optics, 45, 3893-3901.

Stacey, M. T., S. G. Monismith, and J. R. Burau. 1999. Measurements of Reynolds stress profiles in unstratified tidal flow. J. Geophys. Res.-Oceans, 104, 10933-10949.

Tankersley, R. A., L. M. McKelvey, and R. B. Forward, Jr. 1995. Responses of estuarine crab megalopae to pressure, salinity and light: implications for flood tide transport. Mar. Biol., 122, 391-400.

Tennekes, H. and J. L. Lumley. 1972. A First Course in Turbulence, MIT Press, Cambridge, MA, 300 pp.

Thiriot-Quievreux, C. and R. S. Scheltema. 1982. Planktonic larvae of New England gastropods. V. Bittium alternatum, Triphora nigrocincta, Cerithiopsis emersoni, Lunatia heros, and Crepidula plana. Malacologia, 23, 37-46.

Thorson, G. 1964. Light as an ecological factor in the dispersal and settlement of larvae of marine bottom invertebrates. Ophelia, 1, 167-208.

Tiwari, S. and S. Gallager. 2003. Machine learning and multiscale methods in the identification of bivalve larvae, In Ninth IEEE International Conference on Computer Vision, volume iccv, vol. 1, 494 pp.

Trowbridge, J. H., W. R. Geyer, M. M. Bowen, and A. J. Williams III. 1999. Near-bottom turbulence measurements in a partially mixed estuary: Turbulent energy balance, velocity structure, and alongchannel momentum balance. J. Phys. Oceanogr., 29, 3056-3072.

Turner, E. J., R. K. Zimmer-Faust, M. A. Palmer, M. Luckenbach, and N. D. Pentcheff. 1994. Settlement of oyster (Crassostrea virginica) larvae: Effects of water flow and a water-soluble chemical cue. Limnol. Oceanogr., 39, 1579-1593.

Walters, L. J. 1992. Field settlement locations on marine hard substrata: Is active larval exploration involved? Limnol. Oceanogr., 37, 1101-1107.

Welch, J. M. and R. B. Forward, Jr. 2001. Flood tide transport of blue crab, Callinectes sapidus, postlarvae: Behavioral responses to salinity and turbulence. Mar. Biol., 139, 911-918.

Werner, F. E., R. K. Cowen, and C. B. Paris. 2007. Present capabilities and necessary developments for future studies of population connectivity. Oceanography, 20, 54-69. 
Woodson, C. B., D. R. Webster, M. J. Weissbrg, and J. Yen. 2007. Cue hierarchy and foraging in calanoid copepods: ecological implications of oceanographic structure. Mar. Ecol. Prog. Ser., 330, 163-177.

Young, C. M. 1995. Behavior and locomotion during the dispersal phase of larval life, In McEdward, L., editor, Ecology of Marine Invertebrate Larvae, CRC Press, 249-278 pp.

Received: 16 December, 2009; revised: 14 June, 2010. 